\title{
Los grabados de la Historia de Clavijero: manuscritos pictográficos mexicanos, entre redifusión, invención y olvidos
}

The Clavijero's History engravings: pictographic manuscripts, between rerun, invention and oversights

Patrick Lesbre

Université de Toulouse, CEIIBA

CESXVIII, núm. 30 (2020), págs. 303-347

DOI: https://doi.org/10.17811/cesxviii.30.2020.303-347

ISSN: 1131-9879

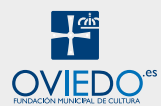




\section{RESUMEN}

En su Historia antigua de México, el jesuita Clavijero reivindica el uso de manuscritos pictográficos mexicanos. Unas láminas copian documentos supuestamente pictográficos como las ruedas calendáricas (siglo, año, mes mexicas). La mayor parte retoman códices ya publicados (principalmente por Purchas, Careri y Lorenzana). Eso se puede comprobar fácilmente con la representación de armas mexicas defensivas. Logra también condensar una forma de saber y presentar nuevos grabados (glifos numéricos, nombres de reyes aztecas, nombres de ciudades) de alcance pedagógico. Clavijero modifica unos glifos voluntariamente para mayor claridad. Los préstamos a los grabados de Carreri menos conocidos (para mostrar vestimentas, armas y regalia mexicas) presentan el mismo interés por el trabajo creativo visible en los grabados. Por fin, otros grabados permiten identificar diversos préstamos más o menos fieles (fabricación de las tortillas) pero también erróneos (temazcal). La representación del Templo Mayor de México, que rechaza la versión fantasiosa de Lorenzana, propone una versión también defectuosa tal como las demás representaciones en materia de religión (templos, sacrificios humanos) porque retoman elementos de grabados del siglo XVI (Valadès) o XVIII (Lorenzana).

Palabras clave

Clavijero, manuscritos pictográficos, Gemelli Careri, Lorenzana, Purchas, aztecas.

\section{AbSTRACT}

In his Ancient History of Mexico published in Italy in 1780, the Jesuit Clavijero, claims the use of Mexican pictographic manuscripts. Some plates copy out documents supposedly pictographic such as calendar wheels (century, year, Mexica months). Most of them retake codex previously edited (mainly by S. Purchas, G. Careri and Lorenzana). This is easily spotted in the Mexica defensive weapons' representation. He also manages to concetrate a form of knowledge and to present new engravings (digital glyphs, Aztec kings' names, cities' names) for educational purposes. Some glyphs are sometimes modified by Clavijero for further clarity. The borrowings from engravings by Careri, less well known, (showing Mexica costumes, weapons and regalia) are just as interesting for the creative work apparent in the engravings. Finally, another more or less scientific engravings permit to identify several borrowings to a certain extent true (the making of bread) but also mistaken (temazcal). The Great Temple of Mexico's representation that rejects Lorenzana's fanciful version, proposes another one just as erroneous like all the other representations showing religious subjects (temples, human sacrifices) because they retake inaccurate elements of 16th century engravings (Valadès) or belonging to the 18th century (Lorenzana).

Key Words

Clavijero, pictographic manuscripts, Gemelli Careri, Lorenzana, Purchas, Aztecs.

Recibido: 16 de enero de 2020. Aceptado: 7 de junio de 2020. 
L'Histoire antique du Mexique publiée en 1780 en Italie par le jésuite Clavijero, expulsé de Nouvelle-Espagne, est un ouvrage qui a marqué l'identité nationale mexicaine au XIXe siècle. Réalisé loin des sources documentaires habituelles, sur le sol européen, il tente l'impossible en faisant flèche de tout bois pour construire une histoire du Mexique préhispanique jusqu'à l'empire et la société aztèques qui sont son principal sujet d'étude. Il réussit à compiler des sources déjà éditées, mais parfois peu connues ou oubliées, principalement du xvie siècle. Parmi celles-ci figurent des manuscrits pictographiques mexicains ou codex dont Clavijero revendique l'usage pour donner à son œuvre une originalité, grâce à plusieurs gravures qui en reproduisent parfois des extraits. Il se démarque ainsi d'ouvrages historiques très solides comme ceux du jésuite Acosta (1590) ou du franciscain Torquemada (1615), publiés sans gravures.

Certaines planches recopient des documents prétendument pictographiques comme les roues calendaires (siècle, année, mois mexicas).

La plupart reprennent des codex déjà édités (principalement par S. Purchas, G. Careri et F. A. de Lorenzana). Cela est facilement visible dans la représentation des armes mexicas défensives. Il parvient aussi à condenser une forme de savoir et à présenter des gravures nouvelles (glyphes numériques, noms de rois aztèques, noms de villes) à visée pédagogique. Si ces emprunts sont connus, ils n'ont pas toujours été vus en détail, en particulier pour les glyphes modifiés volontairement par Clavijero pour plus de clarté. Les emprunts aux gravures de Carreri moins connues (pour montrer costumes, armes et regalia mexicas) sont tout aussi intéressants pour le travail créateur visible dans les gravures.

Enfin des gravures plus ou moins scientifiques, abordées en dernière partie, permettent d'identifier divers emprunts plus ou moins fidèles (fabrication du pain) mais aussi erronés (temazcal). La représentation du Grand Temple de Mexico qui refuse la version fantaisiste de Lorenzana, propose une version tout aussi fautive et révèle l'incompréhension manifeste des pyramides aztèques au XVIIIe siècle malgré l'existence de gravures de glyphes assez précis.

Les autres représentations en matière de religion (temples, sacrifices humains) sont également fautives, car elles reprennent des éléments de gravures du xvie (Valadés) ou du XviIIe siècle (Lorenzana) erronées. 
Revendication de l'usage des manuscrits pictographiques

L'originalité d'inclure des manuscrits pictographiques mexicains est revendiquée dès le titre complet de 1780 :

Storia Antica del Messico. Cavata da Migliori Storici Spagnuoli, e da' Manoscritti, e dalle Pitture Antiche degl' Indiani : Divisa in Dieci Libri, e corredate di carte geografiche, e di varie figure : e Dissertarzioni sulla Terra, sugli Animali, e sugli abitatori del Messico. ${ }^{1}$

Clavijero signale plusieurs codex dans ses sources dès le prologue puisque après avoir énuméré les auteurs des XVIe, XVIIe et XVIIIe siècles ${ }^{2}$, il consacre un quatrième point aux Peintures, c'est-à-dire aux codex mexicains (manuscrits pictographiques indigènes préhispaniques ou coloniaux) qu'il détaille par collections $^{3}$. Il y cite l'actuel Codex Mendoza, et mentionne l'édition de Samuel Purchas. Il renvoie aux codex du Vatican mais indique ne pas avoir pu les consulter à Rome. Il évoque huit codex conservés à Vienne, mais dont un seul a été reproduit en noir et blanc par Eisenach, admettant ainsi ne pas avoir vu les originaux. Puis il cite la collection de Sigüenza (actuel Codex Itlilxochitl) dont Gemelli Careri a reproduit le siècle mexicain, la migration des Aztèques et les portraits de rois mexicains (en réalité tezcocans), tout comme Valadés incluait une gravure du siècle et de l'année mexicains dans sa Rhetorica Christiana. Il dit avoir vu certaines de ces peintures en 1759 à Mexico, évoquant des lois préhispaniques contre certains délits (très certainement la planche 3 de la Mappe Quinatzin actuellement à la BNF). Enfin, il termine avec la collection de Boturini « secuestrada por el suspicaz gobierno de México » dont il a vu certaines peintures concernant la conquête et des beaux portraits de rois de Mexico (très certainement les planches du Codex Ixtlilxochitl représentant Nezahualcoyotl et Nezahualpilli, qui sont en pleine page et contiennent des dorures). Il mentionne une édition en 1770 de 32 pages de tributs, qui correspond à l'édition par Lorenzana et aux gravures reprenant la Matrícula de Tributos. Il passe totalement sous silence le Codex de Florence de Sahagún, qu'il n'a donc manifestement pas connu, et les Primeros Memoriales conservés en Espagne, où il ne peut plus se rendre.

\footnotetext{
1 Francisco Javier Clavijero, Storia Antica del Messico, Cesana, Gregorio Biasini, 1780.

2 Francisco Javier Clavijero, Storia Antica ..., vol. 1, págs. 6-21 «Notizia Degli Scrittori della Storia antica del Meffico».

3 Francisco Javier Clavijero, Storia Antica..., vol. 1, págs. 22-25 «Di Pinture» (tome I, Prologo).
} 
Ses gravures sont parfois accompagnées de pages explicatives, ce qui est le cas pour les gravures à visée pédagogique qui sont regroupées en fin du premier volume et du tome II de l'édition de 1780 : explication des roues calendaires (siècle, année et mois mexicains págs. 248-252); des villes (págs. 253-55), des rois mexicains (págs. 255-256) et du Déluge et de la confusion des langues (pág. 257). La plupart des gravures commentées correspondent aux livres VI et VII.

Pour ne pas appesantir un texte déjà passablement long, nous n'avons pas systématiquement mentionné le graveur ou l'artiste chargé des gravures de l'ouvrage de Clavijero en 1780. Tout comme nous parlons des gravures de Purchas, Carreri ou Lorenzana sans faire état du ou des graveurs chargés de les réaliser ${ }^{4}$. Clavijero ayant accepté et même explicité les gravures présentes dans la première édition, est le responsable des choix et de la présentation didactique : il n'est pas responsable des déformations éventuelles quand l'artiste recopie des gravures plus anciennes. Mais on verra qu'il a pourtant sans doute fait volontairement modifier plusieurs glyphes, dans un but didactique.

\section{Gravures calendaires}

Deux planches recopient des documents prétendument pictographiques, les roues calendaires ( $\mathrm{pl} .8$ et 9$)^{5}$. Les roues calendaires sont produites dès le XVIe siècle par plusieurs chroniqueurs ou religieux non édités à l'époque (dont Motolinía). Clavijero en produit 3 , concernant le siècle de 52 ans, l'année de 18 mois, et le mois de 20 jours. Si la visée pédagogique est indéniable, elle se fait cependant au détriment de la réalité préhispanique, puisque les codex calendaires qu'il a pu voir ne sont pas repris ici, et sont plutôt occultés au profit de roues réalisées par des occidentaux au XVIe siècle et plus compréhensibles pour le lecteur européen.

4 Pour Lorenzana en 1770 on sait qu'est intervenu M. Villavicencio. cf. Miguel Cortés Arrese, « Memorial breve del reformador Lorenzana », in Isidro SÁnchez SÁnchez (coord.), El cardenal Lorenzana y la universidad de Castilla-La Mancha, Ciudad Real, Gabinete del Rector de la Universidad de Castilla-La Mancha, 1999, pág. 40.

5 Les illustrations n'étant pas numérotées, nous reprenons l'ordre d'apparition, en incluant comme première planche la carte géographique du Mexique ancien ("Anahuac o sia l'Imperio messicano ») mais sans compter comme planche la généalogie des rois mexica ("Genealogia dei re messicani »), qui n’a rien d'artistique et est un simple schéma correspondant plutôt à une figure explicative. Les deux roues calendaires (année et mois) sont une seule et même planche. 


\section{Siècle MeXica ${ }^{6}$ (IL SeColo Messicano, Planche 8) ${ }^{7}$}

Cette roue calendaire est dans le goût de l'époque du fait du grand soleil central et du serpent servant de cadre extérieur (dont les anneaux indiquent les débuts de chaque treizaine d'années avec 1 Acatl à gauche, 1 Tochtil en haut, 1 Calli à droite, et 1 Tecpatl en bas). Y sont représentées 52 années aztèques.

Les déformations des glyphes porteurs d'année sont le fait de la gravure de Gemelli Careri (publiée en 1728) ${ }^{8}$, que Clavijero recopie ici, en changeant simplement les éléments centraux par la figure d'un grand soleil (pour masquer son emprunt du disque des fêtes annuelles). Clavijero ajoute en fin de volume une explication de cette roue calendaire correspondant au siècle mexica ${ }^{9}$.

\section{Deux roues calendaires (L'anno Messicano; il Mese Messicano, planche 9) ${ }^{10}$}

Cette planche comporte deux roues calendaires différentes, l'année et le mois mexicas.

L'Année mexica (L'anno Messicano) comporte, en sens contraire aux aiguilles d'une montre, les glyphes des 18 mois de l'année (on reconnaît tecuilhuitl, huey tecuilhuit - petite et grande fête des seigneurs, en 7 et 8-; miquiztli, huey miquiztli - petite et grande fête des morts, en 9 et 10-; pachtli, hueypachtli en 12 et 13 -; etc.). Une lune totalement occidentale occupe le centre du disque ou roue calendaire.

On pourrait tenter de comparer les glyphes des 18 fêtes annuelles avec ceux de la Roue de Boban, mais ils sont différents pour la plupart ${ }^{11}$. En réalité cette

6 Nous corrigeons en mexica (aztèque) l'adjectif mexicain de Clavijero, qui a forgé la conscience nationale mexicaine, mais est désormais ambigu contrairement à 1780 (où il était clairement différencié de l'adjectif novohispanique).

7 Francisco Javier Clavijero, Storia Antica..., vol. 1, pág. 64' (tome II, lib. VI). La numération des pages dans l'édition originale repart à zéro à chaque tome, et non à chaque volume. Nous avons ajouté une apostrophe pour indiquer au lecteur que la page concerne le deuxième tome du premier volume.

8 Secolo Mexicano, Giovanni Francesco Gemeldi Careri, Viaje a la Nueva España, Mexico, UNAM, 1983, pág. 49. Le couteau (Tecpatl) est totalement déformé (pointe plutôt que lame ovale traditionnelle de couteau de sacrifice); le roseau (Acatl) passablement déformé (naturaliste plutôt que sa version calendaire ancienne). La tête de lapin (Tochtli) est occidentale. La maison a un toit trop épais par rapport au glyphe traditionnel pour Calli, maison.

9 Francisco Javier Clavijero, Storia Antica..., vol. 1, pág. 248’ (tome II, Spiegazione..., Delle figure del Secolo Me $\int$ jicano).

10 F. Javier Clavijero, Storia Antica..., vol. 1, pág. 64" (tome II, lib. VI). Les gravures n'ayant pas de pages assignées celle-ci est la seconde, après le Siècle mexicain, à se trouver entre les pages 64 et 65 du tome II.

11 Il suffit de comparer les fêtes de Pachtontli et Huey Pachtli pour voir la différence complète entre les deux roues. 
roue calendaire est une copie exacte de celle de Careri présente au centre de sa gravure du siècle mexicain. Les symboles pour chaque fête sont les mêmes. Clavijero a simplement extrait cette roue, imbriquée par Careri dans une gravure unique, pour en faire un élément d'une autre gravure. On remarquera qu'au passage il a supprimé les indications des phases de la lune (3e disque concentrique dans la gravure de Careri) et remplacé les glyphes des 4 porteurs d'année au centre par une lune totalement occidentalisée. Mais cette même lune occidentalisée était déjà présente dans la Roue du manuscrit de Glasgow fin XVIe siècle (avec un commentaire indiquant que les Indiens appellent leurs mois Lunes) ${ }^{12}$. On observe au passage comment Careri et Clavijero ont supprimé la représentation des nemontemi ou jours non comptés ${ }^{13}$. Le fait de reproduire à nouveau en gravure aboutit à la fameuse inversion, qui oblige Clavijero à proposer un ordre de lecture (indiqué par des chiffres) en sens inverse des aiguilles d'une montre (et donc de Careri). Selon Cañízares-Edguerra, Antonio de León y Gama aurait critiqué Clavijero pour avoir inversé l'ordre des mois Quecholli et Tozoztontli ${ }^{14}$. Chacun des glyphes de mois est explicité dans le commentaire de cette figure en fin de tome $\mathrm{II}^{15}$.

La roue calendaire d'un Mois mexica (il Mese Messicano) comporte les symboles des 20 signes de jours pour un mois. Ils sont explicités dans le commentaire en fin de tome $\mathrm{II}^{16}$. La présence d'un signe de mois (Panquetzalizli, fête des bannières) au centre, fait croire à l'existence de 18 roues possibles (une par mois). Ce que Clavijero fait alphabétiquement dans le commentaire de cette planche et à la fin quand il reprend mois par mois les noms de jours (mais en continu pour faire une année type $)^{17}$. On pourrait croire à une invention de l'auteur pour les roues de mois, mais il indique clairement dans le texte en regard qu'il s'agit d'une copie d'une roue publiée par Valadés dans sa Rhetorica Chris-

12 Diego Muñoz Camargo, Descripción de la ciudad y provincia de Tlaxcala (entre les ff. 177 et 178): «/v. quenta y orden de los meses de todo el año atribuydos a la luna que un mes de veynte dias llamâ una luna. » Clavijero indique avoir copié cette lune d'une peinture mexica : « La figura de la luna que está en el centro de la rueda o círculo del año, está copiada de una pintura mexicana, [...]. » Francisco Javier CLAviJERo, Historia antigua..., Mexico, UNAM, 1983, pág. 285.

13 Clavijero indique cependant avoir vu des roues calendaires les incluant : " He visto algunas ruedas del año mexicano en que, después de las figuras de los diez y ocho meses, había cinco puntos grandes que denotaban los cinco días Nemontemi. » Francisco Javier Clavijero, Historia antigua ..., pág. 285.

14 Jorge Cañizares-Esguerra, How to write de History of The New World, Stanford, Stanford University Press, 2001, fig. 5.3, pág. 275 et pág. 274.

15 F. Javier Clavijero, Storia Antica..., vol. 1, págs. 248-251 (tome II, Spiegazione..., Delle figure dell' anno).

16 F. Javier Clavijero, Storia Antica..., vol. 1, págs. 252-253 (tome II, Spiegazione..., Delle figure del Mese).

17 F. Javier Clavijero, Storia Antica..., vol. 1, págs. 234-247 (tome II, Calendario Messicano); Historia antigua..., págs. 275-283. 
tiana $^{18}$. Simplement Clavijero agrandit et permet de mieux voir un élément noyé dans une gravure de Valadés infinivement plus complexe ${ }^{19}$.

Il serait trop long de discuter ici les sources de ces gravures, qui reviennent plutôt à analyser les roues calendaires qui auraient inspiré ou qu'aurait copiées Careri.

On voit bien à travers ces trois gravures de roues calendaires, comment Clavijero emprunte à Careri (qu'il n'hésite pas à redécouper et subdiviser, tout en modifiant quelques éléments), mais aussi à Valadès (publié en 1579). Il n'invente rien. Simplement il expose différemment pour rendre l'ensemble plus compréhensible. Passer d'une représentation du siècle (4 treizaines d'années), à une représentation de l'année (18 mois de 20 jours), puis à une représentation du mois (20 signes de jour) permet d'exposer pas à pas les arcanes des calendriers préhispaniques, qui ont posé tant de problèmes aux premiers chroniqueurs espagnols du Xvie siècle ${ }^{20}$.

\section{Réemploi de gravures de codex : Purchas, Careri et Lorenzana revus par Clavijero}

Plusieurs gravures sur la société aztèque (armures, boucliers, noms de villes) reprennent des éléments des gravures du Codex Mendoza édité par Purchas en 1625 ou de la Matrícula de tributos éditée par Lorenzana en 1770. Sans parvenir à offrir un codex inédit, Clavijero parvient à condenser une forme de savoir et à présenter des gravures nouvelles (glyphes numériques, noms de rois aztèques, noms de villes) à visée pédagogique. Son livre redonne ainsi aux glyphes traditionnels aztèques une portée qui complète les premières impressions de codex au XVIIe siècle. Il aurait été intéressant de présenter les emprunts

18 F. Javier Clavijero, Historia antigua..., pág. 181 : «Para representar los mexicanos el mes pintaban una rueda dividida en 20 figuras significativas de los 20 días, como se muestra en nuestra lámina, que es copia de la que halla en la Retórica Cristiana de Valadés. »; pág. 285 : « en la única rueda del mes mexicano publicada hasta ahora (la de Valadés), la figura es [...]. »

19 Fr. Diego Valadés, Retórica Cristiana, Mexico, FCE, 1989, pág. [245]. L'auteur renonce à l'expliciter : "Sin embargo, quiero advertir de antemano al lector que he omitido la explicación del calendario de los indios; porque para ponerla debería hacerlo en su propia lengua. », Ibid. pág. [241] (pág. 100 de l'édition originale en latin). On perçoit ainsi mieux l'intention didactique de Clavijero et son travail de recherche très poussé.

20 Deux documents reflètent bien les difficultés de compréhension des Espagnols du xvie siècle face à ces calculs calendaires amérindiens. Les dessins des Primeros Memoriales de Sahagún montrent comment il confond encore les glyphes d'années et les glyphes de jour par l'usage de cartouche et de couleurs non adéquats. cf. Sahagún, Primeros Memoriales, Real Palacio, ff. 283r-302r. On trouve également cet embarras dans les nombreuses planches du Codex Magliabechi, reproduisant les 52 glyphes d'années d'un siècle aztèque par planches et groupes de deux (soit un total de 26 planches, peu pratique à comprendre dans son ensemble). cf. Codex Magliabechi, ff. 15r-27v. 
par auteur, mais ceux de Purchas et Lorenzana sont souvent imbriqués : nous avons donc choisi d'expliciter chaque planche de Clavijero plutôt que de balloter le lecteur d'une planche à l'autre. Nous présenterons cependant à la fin des emprunts à Gemelli Careri moins connus, car ils n’ont quasiment jamais été analysés jusqu'à présent.

\section{LES ARMES MEXICAS DÉFENSIVES : ARMURES, BOUCLIERS CLASSIQUES}

Les représentations d'armes mexicas défensives classiques sont essentiellement reprises de Lorenzana. Clavijero y consacre deux planches (10 et 11).

Armures meXicas (ARMADURE MESSICANE, Planche 10) ${ }^{21}$

Cette planche reprend six bannières et vêtements militaires de haut rang aztèques, manifestement récupérés de la copie de la Matricula de tributos publiée par Lorenzana en 1770.

Apparemment Clavijero n'a pas voulu reprendre les armures présentes dans les premières provinces tributaires du Codex Mendoza copiées par Pur$\operatorname{chas}^{22}$. Purchas en effet n'a pas recopié la totalité des tributs du Codex Mendoza mais les a regroupés par genres, laissant donc de côté plusieurs variantes d'armures et bannières. Contrairement à l'édition de Lorenzana de la Matrícula de tributos qui reprend les provinces tributaires une à une, même si elles sont fortement occidentalisées.

La planche 3 de Lorenzana (province tributaire de Tepetlacalco) fournit déjà trois (voire quatre) des six armures représentées. On y reconnaît sans problème (avec simplement l'inversion habituelle d'orientation des gravures), les

${ }^{21} \quad$ F. Javier Clavijero, Storia Antica..., vol. 1, pág. 142' (tome II, lib. VII).

22 Samuel Purchas, Hakluytus Posthumus or Purchas his pilgrimes, London, Henry Fetherstone, 1625 : pág. 1080 tribut de Huiznahuac (éléments $\mathrm{F}$ et $\mathrm{G}$ pour la même armure à coiffe anguleuse surmontée de deux « antennes » de papier ou coton); pág. 1081 tribut Petlacalcatl (éléments L, N qui incluent une bannière type Xolotl et un casque anguleux). Cependant la dernière armure ressemble en partie (malgré son occidentalisation forte) à celle de Purchas pour le tribut de Cuetlaxtlan. Samuel Purchas, Hakluytus Posthumus..., pág. 1099 tribut de Cuetlaxtlan (élément B). Les rayures horizontales sont bien plus prononcées et la coiffe conique a un décor encore correct. Les armures 2 et 3 peuvent également coïncider en partie avec celles du tribut de Petlacalcatl, malgré la déformation du heaume de Mictlantecuhtli. Samuel Purchas, Hakluytus Posthumus..., pág. 1081 tribut Petlacalcatl (éléments $\mathrm{P}$ et $\mathrm{R}$ ) pour l'armure à décor de Mictlantecuhtli et celle de chevalier jaguar. On pourrait reconnaître l'armure 4 et l'armure 1 dans deux versées par la province de Quauhnahuac : Samuel Purchas, Hakluytus Posthumus..., pág. 1082 tribut de Quauhnahuac (éléments C pour la coiffe de plumes, et $\mathrm{G}$ pour la bannière en forme de papillon). Mais elles sont tellement déformées qu'on hésite à les identifier. Quoi qu'il en soit il manque encore le modèle pour l'armure 5 dans les gravures de Purchas, sans doute parce qu'elle n'y figure pas. 
armures 2 et 3 (qui se suivent, tout comme dans Lorenzana, sur la 2e ligne de tributs vestimentaires militaires), ainsi que l'armure 1 (en sautant une armure qui s’insère entre apparaît dans Lorenzana). Enfin l'armure 4 semble être la dernière de la première ligne de Lorenzana pour cette même province tributaire ${ }^{23}$. L'armure 1 à bannière en forme de papillon est plus proche de celle de la province de Quauhnahuac, où la bannière est posée sur le costume ${ }^{24}$.

En piochant dans l'édition de la Matrícula par Lorenzana six « armures » de son choix, Clavijero revient à l'enquête réalisée par Sahagún au Xvıe siècle, qui compilait les différentes sortes de bannières, de boucliers, d' " armures ${ }^{25}$. Mais il ne souhaite pas être exhaustif et se contente d'un choix limité.

Boucliers meXicas (SCUdi MESSICANI, PLANCHE 11) ${ }^{26}$

Parmi d'autres éléments, cette planche reprend trois boucliers mexicas dont deux ronds avec plumes inférieures, et décor de grecque ou bandes horizontales. Cependant, en regardant de plus près les gravures de 1625 pour les tributs incluant des boucliers, les décors ne correspondent pas vraiment. Globalement on trouve plusieurs boucliers avec décor de grecque géométrique mais aucun ne correspond précisément à celle de la planche de Clavijero ${ }^{27}$. On reconnaît aussi les trois petites demi-lunes dans la partie basse du décor du premier bouclier, mais le reste n'est pas du tout correspondant ${ }^{28}$. De plus d'autres boucliers sont visibles dans les gravures de tribut par Purchas (sans compter tous ceux des scènes d'apprentissage militaire), mais ne sont pas repris par Clavijero $^{29}$. Il en va de même avec l'édition de 1770 de la Matrícula de tributos par Lorenzana. On y dénombre au moins six modèles de boucliers d'apparat dif-

23 Francisco Antonio de Lorenzana, Historia de Nueva-España, escrita por su esclarecido conquistador Hernán Cortés, aumentada con otros documentos y notas, Mexico, Antonio de Hogal, 1770, pl. 3 (Tepetlacalco). [Pour simplifier, nous numérotons de 1 à 32 les 32 planches de Lorenzana qui recopient la Matrícula de Tributos et nous désignerons à part la planche concernant le Grand Temple de Mexico].

24 Francisco Antonio de Lorenzana, Historia de Nueva-España..., pl. 5 (Quauhnahuac). Elle apparaît à la fin de la 2e ligne de tribut en partant du haut.

${ }_{25}$ En particulier dans les Primeros Memoriales, comme par exemple RAH fol 76v pour 4 bannières.

26 F. Javier Clavijero, Storia Antica..., vol. 1, pág. 150' (tome II, lib. VII).

27 Samuel Purchas, Hakluytus Posthumus..., pág. 1080 tribut de Huiznahuac (élément M) mais la grecque inclut un triangle supérieur qui n'est en contact avec rien d'autre; pág. 1081 tribut Petlacalcatl (élément M) mais la grecque est très déformée notamment sur le côté dextre.

28 Samuel Purchas, Hakluytus Posthumus..., pág. 1081 tribut Petlacalcatl (éléments Q et S); pág. 1082 tribut Quauhnahuac (élément D); p. 1099 tribut de Cuetlaxtlan (élément C);

29 Samuel Purchas, Hakluytus Posthumus..., pág. 1080 bouclier à décor de gouttes de pluie (tribut de Huiznahuac élément L); pág. 1081 bouclier à demi cercle noir gauche (tribut Petlacalcatl élément 0 ); pág. 1082 bouclier à décor de triangle et 4 bandes noires, bouclier à décor de patte d'aigle (tribut Quauhnahuac, éléments $\mathrm{F}$ et $\mathrm{H}$ ); etc. 
férents ${ }^{30}$, mais Clavijero n'en garde que deux, les plus emblématiques. Ce sont ceux qui figurent majoritairement sur certaines planches tributaires, où sur 8 modèles de boucliers 6 ou 7 sont les deux motifs choisis par Clavijero (décor de 3 demi-lunes ou grecque géométrique $)^{31}$, voire même parfois les seuls modèles présents $^{32}$. On signalera que Clavijero ne reprend pas l'erreur de glose commise par Lorenzana, qui explicite pour ces boucliers « vestido que sirve de el cuello abaxo ", ou "Vestido de plumas para de medio cuerpo abaxo ${ }^{33}$. C'est ce qu'il indiquait de façon générale dans son prologue ${ }^{34}$.

On signalera aussi qu'à strictement parler, aucun des boucliers présents dans l'édition de Clavijero ne correspond exactement aux modèles proposés par Lorenzana : celui à motif de demi-lunes inclut 4 minces bandes horizontales, quand Lorenzana en présente 3. Celui à motif de grecque a une pointe supérieure droite qui rejoint quasiment une autre pointe triangulaire, détail qu'on ne retrouve pas chez Lorenzana. Bien évidemment, la forme des plumes inférieures n'est pas du tout la même, plus étroite chez Clavijero, plus large chez Lorenzana.

Le troisième bouclier est ovale comme pour la planche représentant le sacrifice dit 'gladiatorial', tout comme le maquahuitl erroné. Ces erreurs ne sont pas le fait de Clavijero, mais remontent à Careri, comme nous le verrons plus bas ${ }^{35}$.

En piochant dans l'édition de la Matrícula par Lorenzana deux boucliers de son choix, parmi les nombreux modèles payés en tribut existants, Clavijero revient à l'enquête réalisée par Sahagún au Xvie siècle, qui compilait aussi dif-

30 Francisco Antonio de LoRenZana, Historia de Nueva-España..., bouclier à motif d'eau (pl. 2 Huiznahuac); motif à patte d'aigle (pl. 3 Tepetlacalco; pl. 4 Acolmecatl), motif à rayures noires avec demi disque (pl. 3 Tepetlacalco); motif à 4 points noirs (pl. 6 Huaxtepec : sans doute une déformation du motif qui suit); motif à 4 bandes noires et triangle noir (pl. 3 Tepetlacalco : sans doute une déformation du dernier motif énuméré ici); motif à 4 rayures noires et triangle noir (pl. 13 Ocuilan, pl. 17 Tepequacuilco).

31 Francisco Antonio de Lorenzana, Historia de Nueva-España..., pl. 4, 5, 6 (Acolmecatl, Quauhnahuac, Huaxtepec : 8 boucliers dont 7 suivent ces deux modèles).

32 Francisco Antonio de Lorenzana, Historia de Nueva-España..., avec des planches qui incluent les deux modèles et d'autres qui n'en reprennent parfois qu'un seul. Planches où alternent les 2 modèles exclusivement : pl. 7 (Quauhtitlan : 5 boucliers); pl. 8 (Huipustla : 6 boucliers); pl. 9 (Atotonilco : 4 boucliers); pl. 10 (Xilotepec : 2 boucliers); pl. 12 (Toluca : 3 boucliers); pl. 19 (Tlapan : 2 boucliers); pl. 20 (3 boucliers); pl. 21 (Chalco : 2 boucliers); pl. 27 (Cuetlaxtecatl : 3 boucliers); pl. 28 (Tlapacoya : 2 boucliers); pl. 29 (Tlatlauhquitepec : 2 boucliers); pl. 30 (Tuxpa : 2 boucliers). Certaines planches ne reprennent que le motif à demi-lunes : pl. 11 (Quahuacan : 3 boucliers); pl. 23 (Coaixtlahuaca : 2 boucliers); pl. 32 (Tazco : 3 boucliers). Une planche ne reprend que le motif de grecque : pl. 16 (Taxco : 2 boucliers).

33 Francisco Antonio de Lorenzana, Historia de Nueva-España..., pl. 2 (Tlatelolco). La planche correspondante dans le manuscrit original étant à moitié détruire, il est impossible de savoir si Lorenzana recopiait ou traduisait correctement une glose plus ancienne.

34 F. Javier Clavijero, Historia antigua..., pág. XXXVII : « [...] y hay mil despropósitos en la interpretación de las figuras, ocasionados por la ignorancia en las antigüedades y en la lengua mexicana. » (pág.

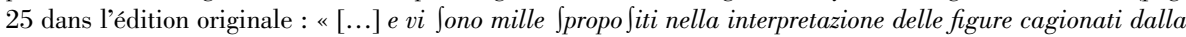
ignoranza dell' antichita, e della lingua me $\int$ Sicana. "

35 cf. Infra, planches 11 et 7 de Clavijero analysées pág. 332-33. 
férentes sortes de de boucliers ${ }^{36}$. Mais, tout comme lui, il ne peut être exhaustif et se contente d'un choix limité : Sahagún le réduisait à quatre modèles de boucliers dans les Primeros Memoriales, Clavijero à deux en 1780.

\section{Caractères numériques et figures symboliques (CARATteri numerali E FIGURE SIMBOLICHE, PLANCHE 15$)^{37}$}

La partie supérieure reprend les glyphes numériques (unités, 20, 400, 8000) avec un souci pédagogique : Clavijero alterne nombres présents dans les codex $(40,800,16000)$ et nombres nouveaux. Il indique ainsi plusieurs combinaisons arithmétiques non présentes dans les codex connus à son époque, mais qui parlent aux lecteurs comme 21, 420, 8400. Ainsi le lecteur comprend facilement comment combiner unités, dizaines, centaines et milliers. Surtout Clavijero propose un exemple concret avec l'année 1780 (et le glyphe xihuitl symbole de l'année, à gauche) en glyphes numériques aztèques : " cio el anno 1780 ». Le lecteur peut ainsi s'approprier l'arithmétique aztèque et ses glyphes numériques.

La partie inférieure inclue plusieurs figures symboliques glosées (8 de A à I puis L) pour jour, nuit, mi-nuit, année, siècle, ciel, air, terre, eau, déluge et confusion des langues. La plupart sont tirées du Codex Mendoza publié par Purchas en 1625 (baptême, éducation des enfants ou des prêtres novices).

On reconnaît en partie le glyphe en rosette pour le jour ${ }^{38}$, dépourvu des quatre petits points formant un carré. On voit bien, à travers cet exemple, que Clavijero suit l'édition de Purchas plutôt que le modèle de celle de Lorenzana, beaucoup plus chargée ${ }^{39}$.

On reconnaît également le rectangle du ciel repris du nom de Moctezuma Ilhuicamina ${ }^{40}$, même si le glyphe de Vénus y est remplacé par cinq points blancs au même emplacement ou que certaines strates du ciel étoilé ne sont pas tout à fait les mêmes. Ce glyphe est absent de l'édition de Lorenzana.

36 ef. Fr. Bernardino de Sahagún, Primeros Memoriales, RAH fol 75v qui contient 4 boucliers d'apparat.

37 Francisco Javier Clavijero, Storia Antica..., vol. 1, pág. 192' (tome II, lib. VII).

38 Samuel Purchas, Hakluytus Posthumus..., p. 1102. Les rosettes pour le glyphe du jour sont représentées quatre fois au-dessus du berceau d'un nouveau-né (élément B dans la gravure). Ces mêmes rosettes se retrouvent dans le tribut versé pág. 1080 (scène K dans la gravure). Clavijero semble reprendre ces modèles, en oubliant les 4 petits points.

39 Francisco Antonio de Lorenzana, Historia de Nueva-España..., pl. 2 (Huiznahuac) : l'intérieur des rosettes y est hachuré et le point central centre est décoré d'un point noir.

40 Samuel Purchas, Hakluytus Posthumus..., pág. 1074 reprend le glyphe du ciel avec ses différentes strates. Curieusement, Clavijero ne reprend pas le glyphe de Vénus dans la bande inférieure et le remplace par de simples disques blancs. 
Figure 1 : glyphe traditionnel de la nuit réinterprété comme minuit par Clavijero très certainement du fait de la présence du glyphe yoalli (nuit) dans le toponyme Yoallan repris comme nuit [entière] par Clavijero. Possible sur-sémantisation du glyphe traditionnel
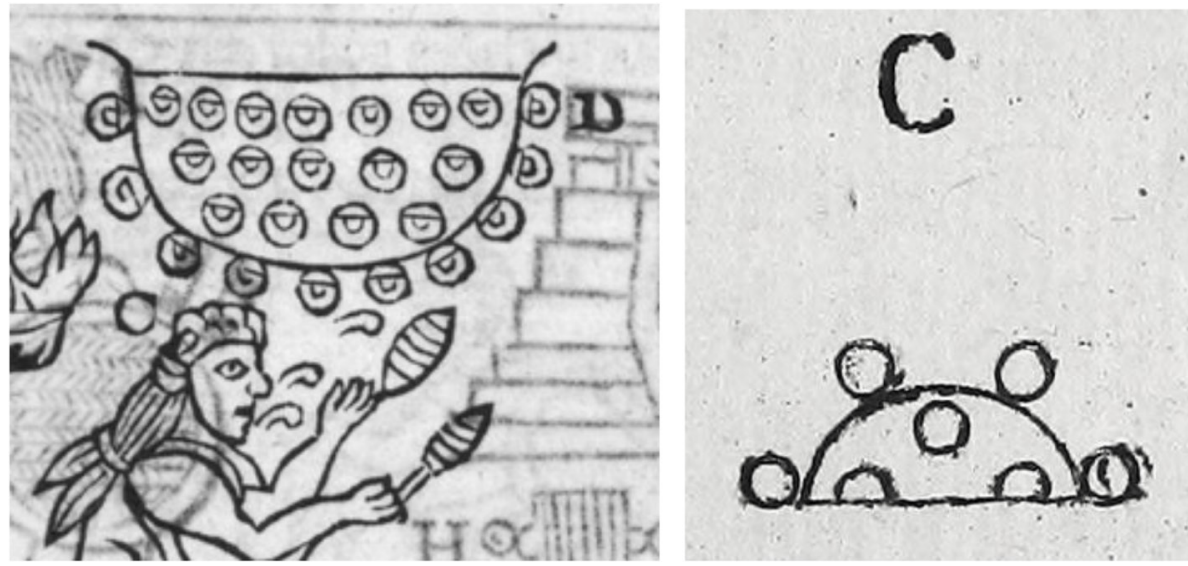

Figure 1a : glyphe traditionnel de la nuit (Purchas, p. 1109) repris par Clavijero (pl. 15, élément $C, 1780)$
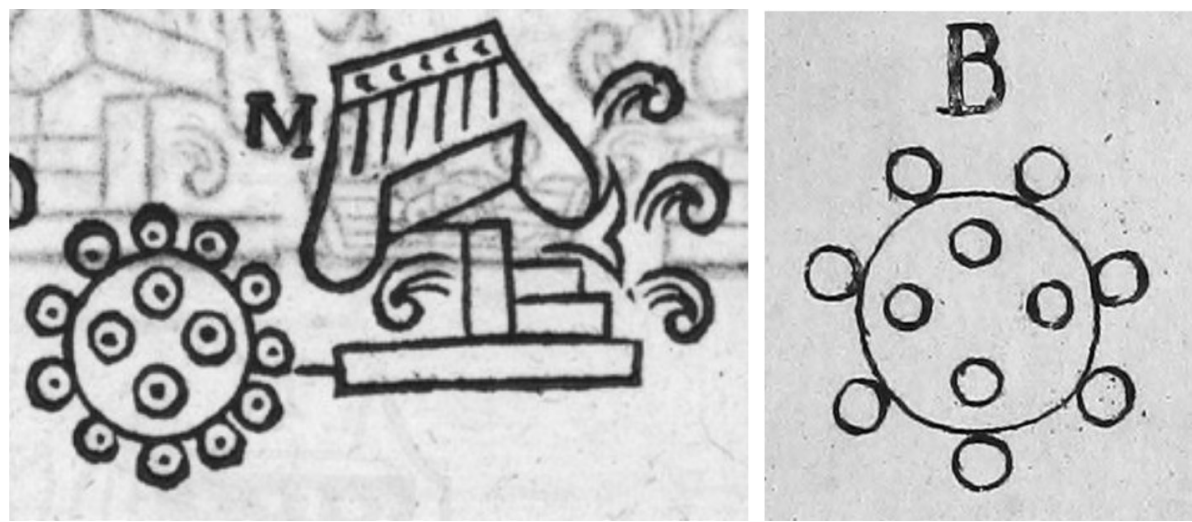

Figure $1 b:$ glyphe toponymique de Yoallan comme ville conquise (Purchas, p. 1073) repris par Clavijero comme nuit (pl. 15, élément B, 1780)

Inversement le glyphe pour minuit (cf. fig. 1) semble ne pas reprendre exactement la version du Codex Mendoza. En effet dans l'original (folio 63r) et la gravure de 1625, le ciel nocturne n'est qu'un demi disque mais de grande taille avec une vingtaine d'étoiles représentées et deux prolongations du contour du ciel ${ }^{41}$.

41 Samuel Purchas, Hakluytus Posthumus..., pág. 1109 reprend parfaitement deux glyphes du ciel nocturne étoilé associé à l'apprentissage de deux prêtres (un musicien, un astronome). 
Clavijero semble avoir simplifié le glyphe et l'avoir retourné en ne gardant que la moitié supérieure, quand la version publiée du Codex Mendoza gardait la moitié inférieure. De plus le commentaire de Purchas, inspiré des gloses espagnoles du Codex Mendoza, ne parle pas de minuit mais de nuit (« in the night» pour les personnages $\mathrm{A}, \mathrm{C}$ et $\mathrm{F}$ de la première ligne) ${ }^{42}$. Il aurait donc forcé l'interprétation de ce glyphe. La lecture comme minuit pour demi-disque nuit est une possible surlecture du glyphe de la nuit du Codex Mendoza.

On pourrait croire que Clavijero a ainsi inventé une variante avec un disque complet pour indiquer la nuit (chose non avérée dans les codex), et un demi-disque qui indiquerait minuit (cf. fig. 1). Cependant le glyphe entier pour la nuit n'est pas une invention de Clavijero mais une lecture attentive des glyphes présents dans la copie de 1625 du Codex Mendoza par Purchas ${ }^{43}$ : parmi les conquêtes d'Itzcoatl figure en effet Yoalan ${ }^{44}$, dont le glyphe semble avoir inspiré celui de Clavijero (et non celui de Yoaltepec légèrement distinct) ${ }^{45}$. On rappellera que ces pages ne sont pas inclues dans l'édition de Lorenzana, et qu'elles indiquent donc le patient travail de recherche mené par Clavijero pour trouver des glyphes intéressants, quitte à les identifier dans des toponymes de villes soumises à l'empire aztèque. C'est ce qu'il indiquait, de façon discrète, dans son prologue ${ }^{46}$.

On pourra être surpris par les choix de Clavijero pour les glyphes de la terre et de l'eau. Leur forme n'a plus rien à voir avec les glyphes présents dans les toponymes des villes conquises ou villes tributaires du Codex Mendoza ou de la Matrícula de tributos. Le glyphe de Clavijero pour la terre a une forme courbe, totalement opposée aux rectangles plus ou moins épais et diversement décorés du Codex Mendoza ${ }^{47}$. Celui de l'eau a également une forme courbe, avec un pa-

42 Samuel Purchas, Hakluytus Posthumus..., pág. 1109 : « A chiefe Priest which goeth in the night... "; « C A chiefe Priest, which is playing on the Teponaztle, ... in the night "; «F A chiefe Priest which is looking on the starres of the Element by night, to set what houre it is in the night..."

43 Clavijero mentionne cet ouvrage dès son prologue : " publicada por Samuel Purchas en el tomo III de su colección. » F. Javier Clavijero, Historia antigua..., pág. XXXV (p. 22 dans l'édition originale : « pubblicate da Samuel Purchas nel tomo terzo della Jua raccolta. »).

44 Samuel Purchas, Hakluytus Posthumus..., pág. 1073 (scène M dans la gravure). Le glyphe toponymique est bien celui d'un disque entier, couvert de petits disques avec un point intérieur, autant d'yeux qui représentent les étoiles. On en compte 4 intérieurs et 10 sur le pourtour extérieur.

45 Samuel Purchas, Hakluytus Posthumus..., pág. 1075 (scène E dans la gravure). Le glyphe toponymique basé sur celui de la nuit, est cette fois constitué de cercles concentriques avec un seul petit cercle au centre, et 8 autres sur le pourtour extérieur.

${ }^{46}$ F. Javier Clavijero, Historia antigua..., pág. XXXV : « Esta colección de Mendoza la he estudiado con diligencia y me ha sido útil para mi historia. " (p. 23 dans l'édition originale : "Questa collezione del Mendoza è Stata da noi diligentemente Studiata, e ci ha recato qualche vantaggio per la I toria. »).

47 Samuel Purchas, Hakluytus Posthumus..., pág. 1106 reprend le grand rectangle avec ses motifs intérieurs, sur lequel un jeune garçon de douze ans est allongé, pieds et mains liées, en punition (scène $\mathrm{N}$ dans 
nache final (où alternent petits disque et formes pointues), qu'on ne trouve pas dans le Codex Mendoza ni la Matrícula ${ }^{48}$, comme on peut le voir en comparant les glyphes anthroponymiques d'Axayacatl et d'Ahuizotl.

La terre et l'eau semblent empruntées à Gemelli Careri, plus précisément à la gravure de Nezahualpilli rendant la justice ${ }^{49}$, avec le glyphe (non compris) atl tlachinolli pour la guerre. Clavijero a désimbriqué les deux éléments, associés dans la gravure de Careri comme dans l'original, pour signifier l'eau et la terre brûlée, donc la guerre. Sa lecture n'est pas forcément fausse, simplement un peu forcée car c'est plutôt la chose brûlée que la terre proprement dite ${ }^{50}$. Le glyphe de l'eau est correct mais il lui manque son élément initial : du coup il se limite à une bande avec un panache final. Le glyphe de la terre a été reconstitué pour la partie manquante. Curieusement Clavijero n'a pas opté pour le glyphe de la terre pourtant parfaitement visible dans les gravures tirées du Codex Mendoza ${ }^{51}$. Mais son choix du glyphe copié par Careri fin XVIIe est intéressant car il signale qu'il a compris en partie les éléments imbriqués. Il s'est seulement partiellement trompé sur le glyphe de terre (puisque c'est la terre brûlée ou la chose brûlée, donc des flammes, qui serait représenté).

D’autres glyphes sont fantaisistes :

- le glyphe pour l'année n'est pas le disque de turquoise du Codex Mendoza mais un disque avec double croix intérieure (que Clavijero reprend juste au-dessous pour la date de l'année 1780);

- le glyphe de l'air tente d'évoquer le vent, mais reprend plutôt une sorte de tête de dauphin baroque emplumée.

- D'où vient le glyphe censé correspondre prétendument au siècle aztèque ? (sorte de maguey). Sans doute est-ce une tentative de représenter le faisceau de 52 roseaux liés entre eux pour symboliser ce

\footnotetext{
la gravure). Clavijero pouvait aussi reprendre le glyphe du champ présent dans les conquêtes d'Acamapichtli (pág. 1069, scène I pour Xochimilco), ou de Moctezuma Ilhuicamina (pág. 1074, scène B pour Coaixtlahuaca).

48 cf. Samuel Purchas, Hakluytus Posthumus..., pág. 1076 pour Axayacatl, ou tous les glyphes de villes conquises incluant le glyphe de l'eau (Acolman pág. 1070, Tequixquiac pág. 1071, Acolhuacan pág. 1072, Cuitlahuac pág. 1073, Totolapan et Atlatlauhco pág. 1074, Atotonilco deux fois et Tlapacoyan pág. 1075). Purchas n'inclue plus les villes conquises à partir du règne d'Axyacatl, pas plus qu'il ne copie les glyphes toponymiques des villes tributaires de la 2e section du Codex Mendoza.

49 Francesco Gemeldi Careri, Viaje a la Nueva España, Mexico, UNAM, 1983, pág. 41 (1699, tome VI, fig. 3, p. 50). cf. Infra, fig. 7 .

50 La version préhispanique de ce glyphe peut se voir sur le bouclier à figure de coyote en art plumassier du Weltmuseum de Vienne (inv. ${ }^{\circ} 43380$ ). On y voit bien des flammes trifides oranges ou violettes dont la base est constituée du possible glyphe de la terre (motif de chevrons).

51 Samuel Purchas, Hakluytus Posthumus..., pág. 1106 (scène N dans la gravure); pág. 1069 (scène I, Xochimilco); pág. 1074 (scène B, Coixtlahuaca).
} 
laps de temps (ligature des années), mais il n'a rien à voir avec les monuments aztèques (encore inconnus pour l'époque). Il s'agirait donc d'une tentative de recréation à partir des mentions présentes dans les chroniques.

Figure 2 : Départ d'Aztlan et début de la migration aztèque d'après les copies

a) du Mapa de Sigüenza réalisée par Careri (édition de 1728);

b) de la gravure de Careri par l'artiste de Clavijero (1780)

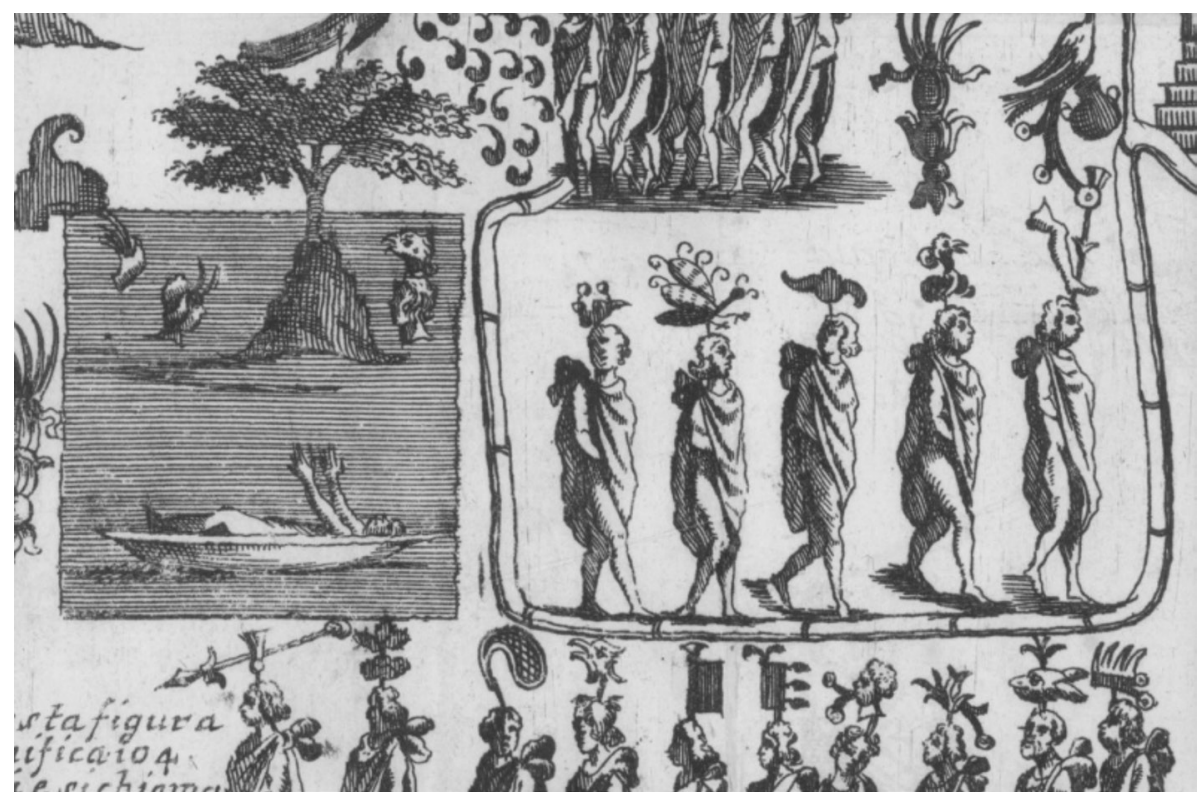

Figure $2 a$

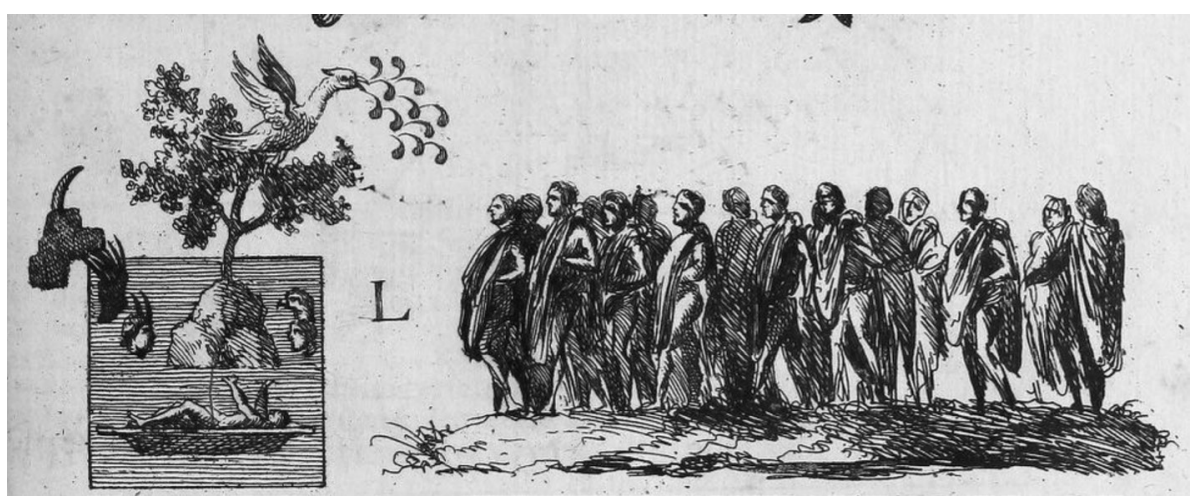

Figure $2 b$ 
Enfin la scène L est empruntée à la copie de la Mappe Sigüenza par Gemelli Carreri $^{52}$ : départ d'Aztlan ici glosé "il diluvio e la confusion delle lingue ». Clavijero ajoute en fin de volume 1 de l'édition de 1780 une explication de cette figure mais sans citer sa source ${ }^{53}$.

On remarquera que la scène de départ d'Aztlan n'est pas exactement reprise (cf. fig. 2) : elle comprend deux éléments (l'aigle proférant ses volutes de parole sur un toponyme posé dans un rectangle avec deux têtes et un canoë; la foule qui l'écoute). Mais ces deux éléments ne sont pas dans leur position exacte : Clavijero a abaissé la foule (et l'a passablement démultipliée et agrandie) pour la mettre non plus à hauteur de l'aigle mais légèrement en dessous (en ajoutant une ligne d'horizon pour le sol, totalement absente de l'original et de la gravure de Gemelli Careri). Pour cela il élimine le début de la migration (les 5 personnages nommés en route à hauteur du carré aquatique).

À cette déformation de la scène de départ d'Aztlan s'ajoute une surlecture biblique. Le carré aquatique est lu par Clavijero comme une allusion au déluge (sans doute inspirée par une scène du Codex Vaticano A, mais qu'il n'a pas reprise $)^{54}$. Les très nombreuses volutes de paroles de l'aigle qui s'adresse aux futurs Mexicas pour qu'ils se mettent en route, sont lues comme la confusion des langues, donc comme Babel ${ }^{55}$. En réalité le commentaire de la gravure de la Mappe Sigüienza par Gemelli Careri est très clair. Dans sa gravure il indique «Luogo di Gaze onde fur detti i mexicani Aztlanechi » et surtout il ajoute devant la glose "Aztlan ${ }^{56}$. Clavijero connaît parfaitement le mythe d'Aztlan, qu'il

52 María Castañeda de la Paz propose plutôt que Clavijero ne se soit pas basé sur la copie de Gemelli Careri mais sur celle d'un auteur inconnu. cf. María CASTAÑEda DE LA PAZ, « El largo periplo de un documento colonial : La Pintura de la Peregrinación de los culhuas-mexitin (El Mapa de Sigüenza) », tomo LIX, I, 2002, págs. 619 et 630-632.

53 F. Javier Clavijero, Storia Antica..., vol. 1, pág. 257' (tome II, Spiegazione..., 6. Della figura del diluvio, e della confu fione delle lingue).

54 Codex Vaticano A, f. 4v (Apachihuilliztli, déluge). cf. F. Javier Clavıjero, Historia antigua..., pág. 287 (lib. VII, Explicación..., Figuras del Diluvio y de la confusión de las lenguas). L'explication concernant le déluge semble reprise d'un manuscrit pictographique type le Codex Vaticano A (pourtant non consulté par Clavijero) se référant aux quatre âges du monde antérieur à celui présent. Clavijero semble projeter ainsi sur la scène de migration une lecture concernant un mythe beaucoup plus ancien : «[...] la cabeza humana y la de pájaro que se ve en el agua, significan la sumersión de los hombres y los animales. La barca con un hombre encima, denota aquella en que, según su tradición, se salvaron un hombre y una mujer para conservar la especie humana sobre la tierra.» Cette lecture confond donc deux mythes, tous deux préhispaniques.

55 F. Javier Clavijero, Historia antigua ..., pág. 287 (lib. VII, Explicación..., Figuras del Diluvio y de la confusión de las lenguas).La lecture de la scène principale est totalement erronée, puisque Clavijero remplace l'aigle ordonnant le départ de la migration aztèque par une colombe : «El pájaro sobre el árbol representa una paloma, la cual, según decían ellos, comunicó el habla a los hombres, pues todos habían nacido mudos después del Diluvio. Las virgulillas que nacen del pico de la paloma hacia los hombres, son figuras de las lenguas. "

${ }_{56}$ Francesco Gemelli Careri, Viaje a la Nueva España, gravure entre les pages 24 et 25 (cap. 5). 
expose dans son Histoire ${ }^{57}$. Mais ici il préfère le taire (voire le censurer en supprimant les cinq chefs de migration représentés à hauteur de la lagune dans la gravure de Gemelli Careri) et proposer une lecture doublement biblique de la scène qu'il explicite en annexe ${ }^{58}$.

3. Noms des rois Mexicas (Figure Significanti i nOMi de Re messicano, Planche 16) ${ }^{59}$

Cette planche comporte les têtes et les glyphes anthroponymiques d'Acamapichtli (Acamapitzin) à Moctezuma Xocoyotzin (Motezuma Xocojotzin). Ces éléments sont fortement occidentalisés par le graveur. La Matrícula copiée par Lorenzana n'incluant que deux noms de souverains de Mexico Tenochtitlan, Clavijero ne peut donc que s'inspirer des gravures du Codex Mendoza de Purchas. Il ajoute en fin de volume une explication des figures de ces rois ${ }^{60}$.

Certains de ces glyphes suivent de près la version de Samuel Purchas de 1625 :

- le glyphe anthroponymique d'Acamapitzin est une main qui tient un faisceau de roseaux plutôt que de flèches (on ne voit pas de pointes ni d'empennes comme dans certains glyphes). Il reprend la version du Codex Mendoza présente dans les gravures de Purchas ${ }^{61}$.

- le glyphe anthroponymique pour Axayacatl a une tête-visage occidentale et le glyphe de l'eau dissocié du front ${ }^{62}$.

- Moctezuma Xocoyotzin est schématisé : la chevelure n’est pas comprise, de même que l'ornement d'oreille (transformé en base) et du labret ou ornement de nez. Mais cette occidentalisation est le fait de la gravure de Purchas que Clavijero reproduit ici fidèlement ${ }^{63}$.

57 F. Javier Clavijero, Historia antigua..., pág. 65 (lib. II, point 17 « Viaje de los mexicanos al país de Anáhuac. »

58 F. Javier Clavijero, Storia Antica..., vol. 1, pág. 257' (tome II, Spiegazione..., 6. Della figura del diluvio, e della con Ju fione delle lingue). cf. F. Javier Clavijero, Historia antigua..., pág. 287 (lib. VII, Explicación..., Figuras del Diluvio y de la confusión de las lenguas).

59 F. Javier Clavijero, Storia Antica ..., vol. 1, pág. 192' bis (tome II, lib. VII).

60 F. Javier Clavijero, Storia Antica..., vol. 1, págs. 255'-256' (tome II, Spiegazione..., 5. Delle figure

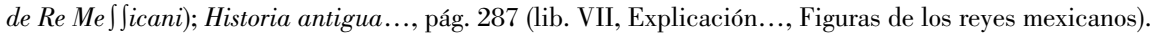

${ }_{61}$ Samuel Purchas, Hakluytus Posthumus..., pág. 1069 reprend parfaitement les deux éléments sans pointes de flèches ni empennes (scène $B$ dans la gravure).

62 Samuel Purchas, Hakluytus Posthumus..., pág. 1076 Axayacatl (scène B dans la gravure). Clavijero n'a pas reproduit le glyphe d'Axayacatl présent dans Lorenzana (pl. 2, Tlatelolco).

63 Samuel Purchas, Hakluytus Posthumus..., pág. 1078 Motecuhzoma Xocoyotzin (scène C dans la gravure). 
Au lieu de représenter les souverains de profil, le graveur a fait un troisquart et surtout une perspective sur le haut aplati de la couronne plutôt que la chevelure ou le haut du crâne dépassant du côté de la xihuitzolli.

Certains de ces glyphes anthroponymiques sont légèrement différents de la version de Purchas.

- Ilhuicamina a bien un glyphe de ciel traditionnel (plus ou moins respecté ${ }^{64}$ mais la flèche est représentée avec sa pointe visible au lieu de plantée dans le ciel.

- Celui de Tizoc est un glyphe énorme d'une jambe occidentale (naturaliste) avec traits. La différence de taille semble héritée en droite ligne des gravures des souverains aztèques par Purchas, même si son glyphe anthroponymique pour Tizoc est couvert de pointillés et non de traits ${ }^{65}$.

- Celui d'Itzcoatl est un serpent dragon (ressemblant à un hippocampe) droit avec les pointes de flèches triangulaires sur petites lignes, très occidentalisé. Si les pointes de flèches sont similaires à celle du glyphe du Codex Mendoza reproduit en 1625 par Purchas, en revanche le haut de la tête du serpent est dépourvu du décor géométrique quadrangulaire encore très visible chez Purchas ${ }^{66}$.

- Le glyphe de nom d'Ahuizotl est également très occidental : l'animal n'est pas compris (pas de spirale pour sa queue ce qui est le cas aussi dans la gravure de Purchas). Le glyphe de l'eau le surmontant n'est pas compris alors qu'il était encore clair dans la gravure de $1625^{67}$ : le graveur travaillant pour Clavijero n'a pas reproduit la couche d'eau (parfaitement visible chez Purchas), et s'est contenté de poser de petites «médailles » directement sur le dos de l'animal.

D'autres sont complètements différents, pour des raisons qui nous échappent :

- Celui pour Huitzilihuitl a quasiment une tête de dinde plutôt que de colibri. Il n'a rien à voir avec le bec fin et les 4 glyphes de duvets encore intelligibles dans la gravure du glyphe anthroponymique tirée du Codex Mendoza par Purchas ${ }^{68}$.

\footnotetext{
64 cf. Supra, note 40.

65 Samuel Purchas, Hakluytus Posthumus..., pág. 1077 Axayacatl (scène B dans la gravure).

66 Samuel Purchas, Hakluytus Posthumus..., pág. 1072 Itzcoatl (scène E dans la gravure).

67 Samuel Purchas, Hakluytus Posthumus..., pág. 1078 Ahuizotl (scène B dans la gravure).

68 Samuel Purchas, Hakluytus Posthumus..., pág. 1070 Huitzilihuitl (scène F dans la gravure).
} 
- Le glyphe anthroponymique de Chimalpopoca n'a pas de volutes de fumées mais 2 éléments en traits (qui ressemblent totalement à la fumée s'échappant du bain de vapeur ou temazcal représenté planche 19). Il n'est manifestement pas repris de la gravure de Purchas, qui inclut 4 volutes de fumées traditionnelles ${ }^{69}$. Le graveur a opté pour une représentation naturaliste de la fumée, tourbillonnante ou s'élevant en spirale et non plus en volutes.

Clavijero est le premier à regrouper les glyphes anthroponymiques des souverains de Mexico Tenochtitlan. Purchas en 1625 reproduit chaque règne séparément, conformément au Codex Mendoza. Carreri avait fait une galerie de portraits de souverains de Tenochtitlan (en changeant l'identité des personnages représentés) mais sans glyphes de noms. Clavijero s'insère dans cette tradition et innove.

Sans le savoir, Clavijero reproduit ainsi quelque chose de similaire aux Primeros Memoriales de Sahagún, qui compilaient tout ces glyphes anthroponymiques mais associés à une représentation complète de chaque seigneur mexica (pour montrer les changements de statut avant la fondation de l'empire aztèque et à la chute de celui-ci) ${ }^{70}$.

\section{Figures de villes (Figure Di CitTA, planche 17$)^{71}$}

Les 16 glyphes toponymiques de villes sont tirés pour la plupart de la copie de la Matricula par Lorenzana. Alors que la planche concernant les souverains ne pouvait qu'être copiée sur Purchas, pour les glyphes de villes Clavijero et son graveur ont l'embarras du choix entre les centaines de villes soumises à l'empire aztèque reproduites par Purchas (sur le modèle du Codex Mendoza, en particulier pour les listes de villes conquises) et par Lorenzana (sur le modèle de la Matrícula de Tributos, pour les provinces tributaires). C'est cependant Lorenzana qui prévaut puisque sur 16 glyphes toponymiques, quatorze sont copiés de Lorenzana.

L'inconvénient en est une forte occidentalisation, alors que les glyphes de la copie de Purchas sont encore très proches du style traditionnel. Cette occidentalisation est déjà le fait de la copie de la Matricula par Lorenzana en 1770. Mais elle est parfois encore plus poussée dans la planche de Clavijero qui est plus tardive (1780).

\footnotetext{
69 Samuel Purchas, Hakluytus Posthumus..., pág. 1071 Chimalpopoca (scène F dans la gravure).

70 Fr. Bernardino de SAhagún, Primeros Memoriales, RAH, f. 5lrv.

71 F. Javier Clavijero, Storia Antica..., vol. 1, pág. 192' ter (tome II, lib. VII).
} 
Certains glyphes sont copiés quasiment à l'identique, le plus souvent ceux ne comportant aucun élément animal ou humain, et donc paradoxalement, les plus énigmatiques pour un lecteur occidental :

- Atotonilco (gl. 6) reprend tous les éléments de la gravure de Lorenzana $^{72}$, en changeant simplement les rayures ou traits par des quadrillages plus fins pour aboutir à un relief plus soigné.

- Tehuillojocan (gl. 9) ressemble à une sorte d'ornement baroque en relief (plutôt qu'une grosse fleur) tout comme la gravure de Lorenzana ${ }^{73}$.

- Tecozauhtla (gl. 16) reprend tous les éléments de la gravure de Lorenzana $^{74}$. Le disque est mieux tracé et plus rond chez Clavijero que chez Lorenzana où il penchait vers une pointe inférieure.

- Macuilxochitl (gl. 14) reprend les mêmes 5 points alignés sous une fleur à double pistil, plus finement tracée. On observe juste que la gravure de l'ouvrage de Clavijero a séparé les cinq points en deux groupes (2 et 3 ) alors qu'il étaient quasiment jointifs chez Lorenzana ${ }^{75}$.

- Tlachco (gl. 15) reprend le glyphe en I majuscule couché d'un terrain de jeu de pelote. La moitié supérieure du terrain est moins finement tracée (simples traits au lieu d'un quadrillage chez Lorenzana). La copie n'est pas parfaite : les anneaux sont dotés d'un point central blanc, quand il est noir chez Lorenzana, et la forme du terrain voit les barres du $\mathrm{H}$ majuscule laisser un espace vide plus prononcé chez Clavijero $^{76}$.

D'autres voient leur occidentalisation encore plus poussée, notamment tous ceux qui comportent des animaux ou un élément du corps humain :

Quauhtinchan (gl. 12) a une tête d'aigle beaucoup plus occidentalisée, quand la gravure de Lorenzana gardait encore l'élément traditionnel caractéristique des plumes d'aigle de la tête ${ }^{77}$. Le glyphe de maison Calli (pour ichan, demeure) a été remplacé par une simple enceinte dans la version de Clavijero. Est-ce une incompréhension du graveur ou une correction voulue par Clavijero pour une étymologie plus correcte?

72 Francisco Antonio de Lorenzana, Historia de Nueva-España..., pl. 9 (Atotonilco el grande).

73 Francisco Antonio de Lorenzana, Historia de Nueva-España..., pl. 7 (Quauhtitlan).

74 Francisco Antonio de Lorenzana, Historia de Nueva-España..., pl. 10 (Xilotepec) : ondulations intérieures claires ou sombres, disque et petits points blancs sur le pourtour.

75 Francisco Antonio de Lorenzana, Historia de Nueva-España..., pl. 24 (Coyolapan).

76 Francisco Antonio de Lorenzana, Historia de Nueva-España..., pl. 10 (Xilotepec).

77 Francisco Antonio de Lorenzana, Historia de Nueva-España..., pl. 22 (Tepeaca) : certaines d'entre elles sont relevées et distinguées. 
L'arrière-train tzintli devient une partie du corps humain qui semble courir (gl. 3) ou tenir debout (gl. 4). Ces déformations sont le fait de l'édition de Lorenzana $^{78}$. L'artiste travaillant pour Clavijero a simplement poussé l'occidentalisation encore plus loin : les pieds sont mieux dessinés et leur mouvement est plus marqué, les genoux mieux en lumière pour Xochitzinco ${ }^{79}$.

Ahuilizapan (gl. 7) reprend un buste d'homme occidental, copié de la gravure de Lorenzana (province de Quauhtochco) ${ }^{80}$. Simplement au lieu d'être de profil et encore indianisant (cheveux bruns), l'homme est représenté de face et occidentalisé (cheveux blonds).

Huaxjacac $\left(\mathrm{n}^{\circ} 5\right)$ est emblématique de cette occidentalisation plus poussée. Alors que le visage humain restait très schématique (sorte de gros haricot) dans la gravure de Lorenzana ${ }^{81}$, il reprend tous ses attributs dans celle de Clavijero. Les deux fleurs sont également mieux représentées.

D'autres enfin sont tout simplement modifiés et non plus simplement plus occidentalisés : deux de ces modifications relèveraient d'une incompréhension manifeste du modèle par le graveur copiste (Atenco, Tlacotepec); deux autres sont par contre des modifications voulues par Clavijero (qui en aurait donc précisé l'instruction à l'artiste).

Cela est presque imperceptible pour le glyphe d'Atenco (gl. 8), fidèlement recopié pour les protubérances du glyphe de l'eau, mais doté d'une mâchoire humaine beaucoup plus prononcée (avec plus de dents, 5 contre 4 en haut). Il semble que le graveur n'ait pas compris qu'il y avait aussi une mâchoire inférieure (peu prononcée chez Lorenzana), et qu'il en ait fait un élément végétal (si on voit deux petits éléments blancs correspondants aux deux dents de la gravure de 1770, ils sont accolés à 6 éléments gris; surtout, la forme du menton a disparu) ${ }^{82}$.

Tlacotepec (gl. 13) est surmonté d'une épée ou d'un couteau métallique. Le graveur de Lorenzana semble avoir pris le glyphe de la colline pour un bouclier, et du coup aurait combiné les deux éléments comme un blason ${ }^{83}$. Mais si les

78 Francisco Antonio de Lorenzana, Historia de Nueva-España.., pl. 9 (pour Tollantzinco glyphe $\mathrm{n}^{\circ} 3$ ) et pl. 12 (pour Xochitzinco glyphe $\mathrm{n}^{\circ} 4$ ). Tout juste les gravures de l'ouvrage de Clavijero incluent une musculature des jambes plus marquée et accentuent un peu le mouvement des pieds.

79 Samuel Purchas, Hakluytus Posthumus..., pág. 1070 Tulancinco (scène H dans la gravure). Le muscle apparent du mollet, pieds mieux détaillés, feuilles de la plante et forme du contenant changent pour Tollantzinco. Alors que le glyphe de Tollantzinco dans la gravure de 1625 comprend bien l'élément $t z i n t l i$ ou arrière-train comme accolé sous la plante et non sur le côté.

80 Francisco Antonio de Lorenzana, Historia de Nueva-España..., pl. 26 (Quauhtochco).

81 Francisco Antonio de Lorenzana, Historia de Nueva-España..., pl. 24 (Coyolapan).

82 Francisco Antonio de Lorenzana, Historia de Nueva-España..., pl. 29 (Tlatlauhquitepec).

83 Francisco Antonio de Lorenzana, Historia de Nueva-España..., pl. 12 (Toluca). 
éléments constitutifs du glyphe traditionnel de la colline (tepetl) sont encore visibles chez Lorenzana (base double, protubérances latérales), ils disparaissent de la version de Clavijero, dans laquelle le graveur n'a manifestement plus du tout compris ce qu'il recopiait et pousse la représentation vers un bouclier exotique (comme le targe ou adarga morisque). Pourtant Clavijero ne semble pas relever ou corriger cette déformation dans son explicitation en annexe ${ }^{84}$.

Michmalojan (gl. 11) présente un poisson plus fortement occidentalisé que la gravure de Lorenzana ${ }^{85}$, et un bras occidentalisant plus musclé, avec un jeu d'ombres et de relief, une perspective. La main est plus réaliste, et surtout elle attrape le poisson, au lieu de rester au-dessus (cf. fig. 3a). Ce changement est important. Il ne s'agit plus d'un élément mal compris, ou mal recopié, mais d'un changement volontaire. Va-t-il dans le sens étymologique du nom de lieu? Antonio Peñafiel propose michin (poisson) et malli (captif) pour indiquer pêcher ${ }^{86}$. Il est possible que Clavijero ait également compris cette étymologie et souhaité la rendre plus compréhensible par le geste de capture du poisson plutôt qu'une simple juxtaposition des deux éléments. C'est ce qu'il explicite en annexe ${ }^{87}$. Le changement aurait donc été notifié à l'artiste au lieu de relever d'une simple incompréhension de copiste. Par contre le coquillage minuscule (cillin) du glyphe de l'eau n'est pas compris et le plus souvent est présenté comme un bourgeon, ce qui relève en l'occurrence d'une erreur de copiste.

Le glyphe de Mexico (gl. 1 Messico) a lui aussi été modifié. Il est assez proche du glyphe de Xoconoxco dans l'édition de Lorenzana ${ }^{88}$. La principale divergence reste cependant que les racines, encore visibles dans la copie de Lorenzana, ont été remplacées par un socle quadrangulaire chez Clavijero (cf. fig. $3 \mathrm{~b})$. Il y a là une modification curieuse, très certainement du fait que Clavijero souhaitait commencer sa liste par un glyphe toponymique de Mexico (Tenochtitlan). Ne le trouvant pas dans les toponymes de la Matrícula, il aurait délibérément copié celui de la province de Xoconochco (pourtant clairement

${ }_{84}$ F. Javier Clavijero, Historia antigua ..., págs. 286 : « 13. Un monte como lo figuraban los mexicanos, y poco más arriba un cuchillo para representar la ciudad de Tlacotepec, que quiere decir monte cortado. » (p. 255 dans l'édition originale).

85 Francisco Antonio de Lorenzana, Historia de Nueva-España.., pl. 10 (Xilotepec). Le poisson de la gravure de Lorenzana est encore proche du glyphe traditionnel, comme on peut le voir f. 46r. du Codex Mendoza pour le lieu appelé Michtlan.

86 Antonio Peñafiel, Nombres geográficos de México, Mexico, ed. Innovación, 1978, pág. 142.

87 F. Javier Clavijero, Historia antigua ..., pág. 286 : « 11. Un brazo que coge un pescado para representar la ciudad de Michmaloyan, que significa lugar en donde se coge el pescado o lugar de pesca. » (lib. VII, Explicación..., Figuras de ciudades); (pág. 255 dans l'édition originale) (nous soulignons).

88 Francisco Antonio de Lorenzana, Historia de Nueva-España..., pl. 25 (Xoconochco). Le glyphe toponymique présente une forme similaire de figuier de barbarie, même si les pétales sont séparés dans la gravure de Clavijero et unis dans celle de Lorenzana. 
Figure 3 : Glyphes toponymiques modifiés par Clavijero pour en renforcer (fig. 3a) ou changer (fig. 3b) l'étymologie

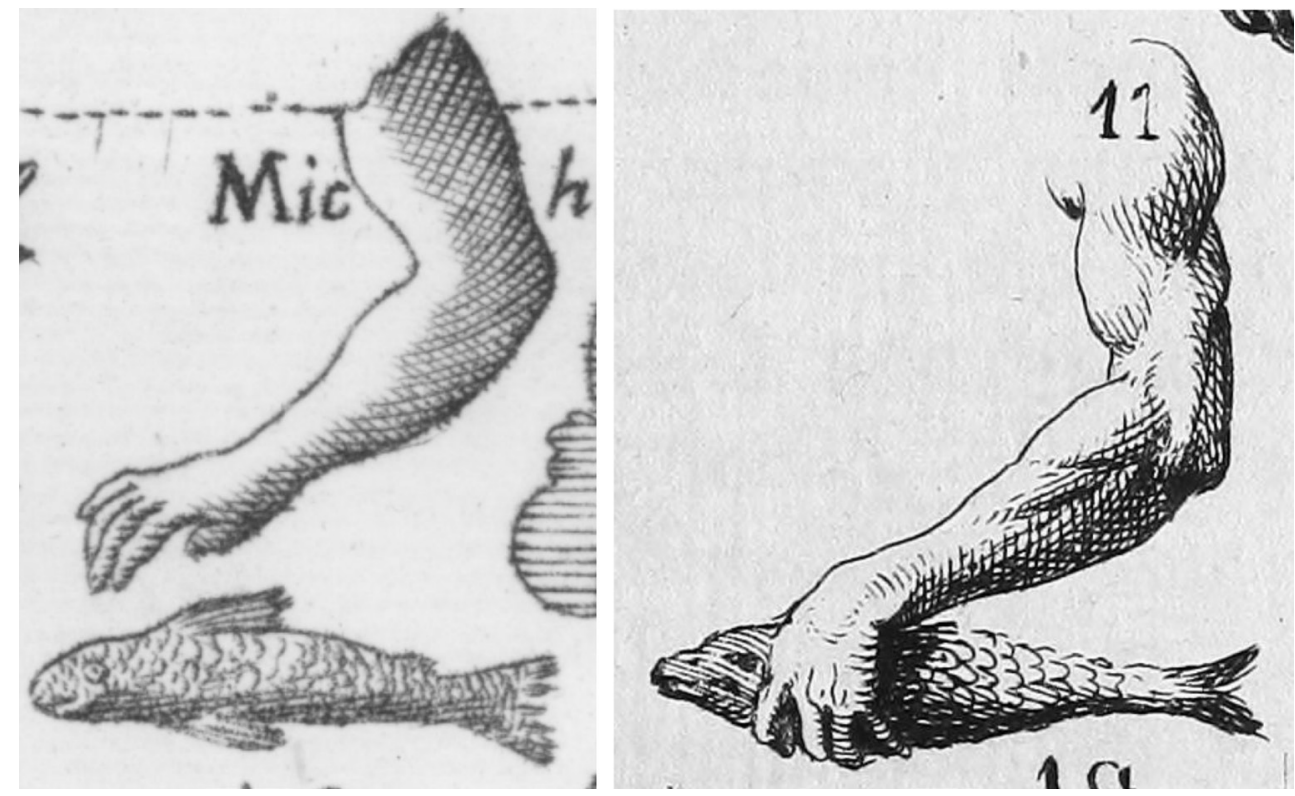

Figure 3a: Michmaloyan dans l'édition de Lorenzana (pl. 10, 1770) et celle de Clavijero (pl. 17, 1780). Le glyphe a été modifié par Clavijero pour en renforcer l'étymologie
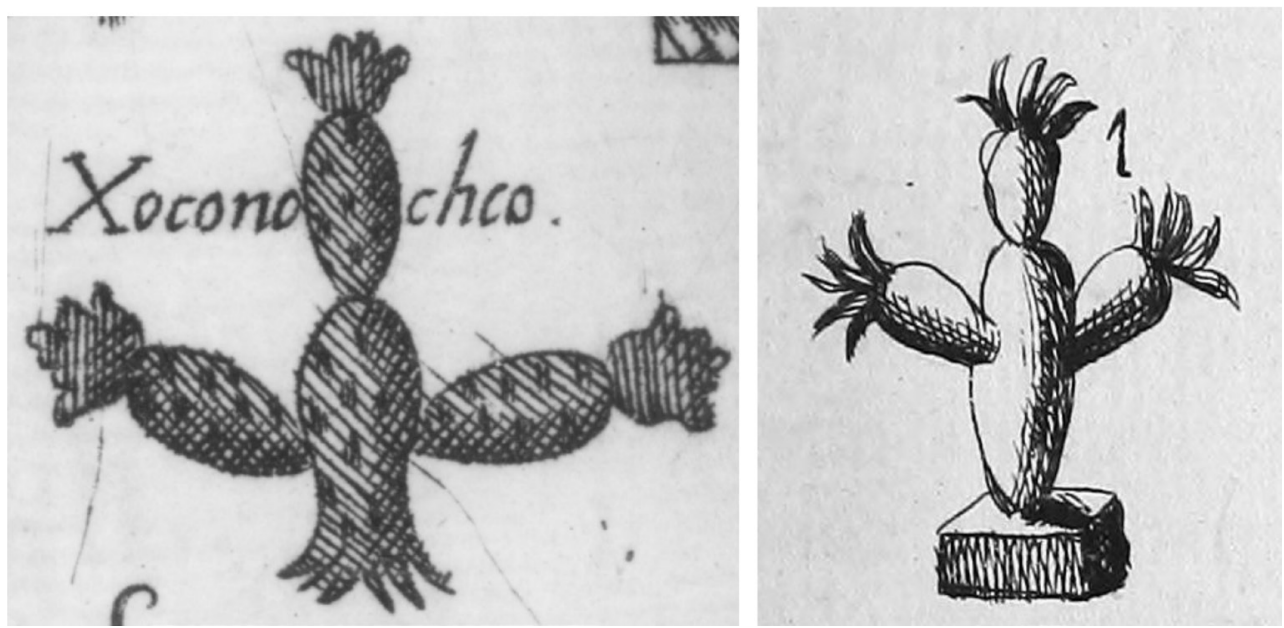

Figure $3 b$ : Glyphe toponymique de Xoconochco (Lorenzana, pl. 25, 1770) transformé en glyphe toponymique de Mexico par l'ajout d'une pierre carrée qui n'a rien à voir avec le glyphe aztèque traditionnel (Clavijero, pl. 17, 1780) 
glosé par Lorenzana) et, en remplaçant les racines du figuier de barbarie par une pierre quadrangulaire, aurait tenté de se rapprocher du glyphe de Tenochtitlan qui inclut l'élément pierre (même si la gravure, en représentant un socle quadrangulaire, ne respecte absolument pas le glyphe traditionnel de la pierre -tetl-). Il y aurait donc modification volontaire (puisque dotée d'un sens précis étymologique) et non incompréhension du copiste.

Seuls deux toponymes ne proviennent pas de la version de Lorenzana : Chalco $\left(n^{\circ} 2\right)$ et Nepohualco $\left(n^{\circ} 10\right)$.

Le glyphe de Chalco (gl. 2) est très schématique et rigide tout comme le glyphe de Tecozauhtla (gl. 16). Il est surtout très différent de celui reproduit dans les gravures du Codex Mendoza par Purchas ${ }^{89}$, ce qui semblerait indiquer que Clavijero se sert bien de la copie de la Matrícula par Lorenzana ${ }^{90}$. Mais la version de Lorenzana est bien plus complexe (le disque est subdivisé en quinze parties au lieu de huit dans la version de Clavijero). Le graveur aurait pu simplifier, mais d'habitude il reste assez fidèle dans ses copies. En regardant plus attentivement, on trouve bien un glyphe similaire pour Chalco dans l'édition du Codex Mendoza par Purchas, pour les conquêtes de Huitzilihuitl et de Moctezuma Ilhuicamina ${ }^{91}$. Ce choix est pour le moins surprenant. Il semble indiquer que Clavijero aurait choisi pour ce glyphe de se distancier de la copie de Lorenzana. Pourtant la version de Lorenzana reste proche de l'original ${ }^{92}$. On ne comprend donc pas vraiment pourquoi ce toponyme n'a pas été copié, comme la grande majorité des autres, dans la version de Lorenzana.

Nepohualco (gl. 10) est une main occidentale à l'index dressé alors que le glyphe de Nepopohualco n'a rien à voir dans la copie de Lorenzana ${ }^{93}$ (cf. fig. 4) puisqu'elle se compose d'un bras posé sur le sommet d'une colline, avec des petits points pouvant indiquer l'action de compter (nepoa, présent dans l'étymologie du nom de lieu). Clavijero a pu procéder à une métonymie, en ne gardant

89 Samuel Purchas, Hakluytus Posthumus..., pág. 1071 et 1073 insère le glyphe habituel de pierre précieuse dans un carré. Le cercle est subdivisé et décoré (scènes $\mathrm{E}$ dans la gravure p. 1071 et $\mathrm{D}$ dans la gravure p. 1073) (Lib. V, Chap. $7 \S 1$ ).

90 Francisco Antonio de Lorenzana, Historia de Nueva-España..., pl. 21 (Chalco) : le disque est quadripartite alors qu'il est subdivisé en huit parties dans la version de Clavijero.

91 Samuel Purchas, Hakluytus Posthumus..., pág. 1070 et 1074 où le cercle est très différent des représentations précédemment citées, beaucoup plus épais et décoré différemment. (scènes D dans la gravure pág. 1070 et L dans la gravure pág. 1074) (Lib. V, Chap. 7 § 1). La liste des conquêtes de Huitzilihuitl semble le modèle suivi par Clavijero, car c'est la seule fois où le glyphe de Chalco n'est pas inséré dans un carré.

92 L'original (Matrícula de tributos, pl. 21) comporte 13 subdivisions au lieu de quinze, mais ce n'est pas une erreur grave et Clavijero n'avait aucun moyen de s'en rendre compte.

93 Francisco Antonio de Lorenzana, Historia de Nueva-España..., pl. 6 (Huaxtepec). La version du Codex Mendoza (f. 25r.) et de la Matrícula (pág. 6) est un bras posé sur le sommet d'une colline, avec des petits points pouvant indiquer l'action de compter. Elle n'est pas copiée par Purchas. 

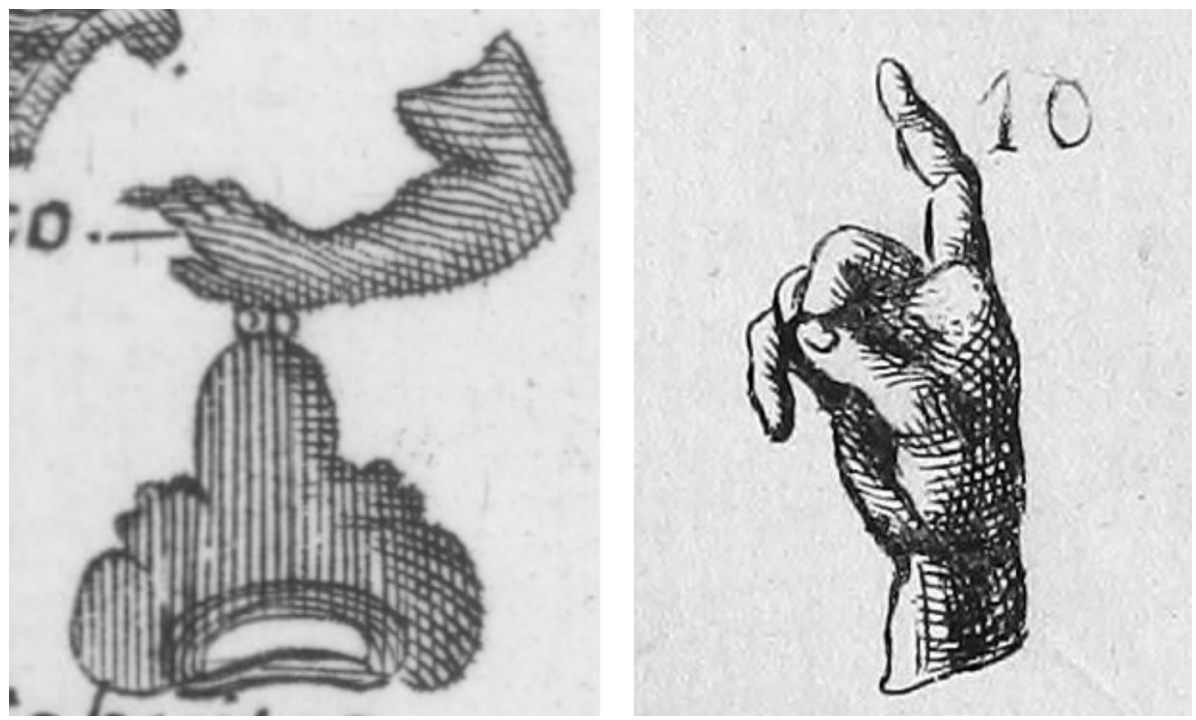

Figure 4 : Glyphes toponymiques de Nepopohualco dans l'édition de Lorenzana (pl. 6, 1770) et de Nepohualco dans celle de Clavijero (pl. 17, 1780). Clavijero a délaissé le glyphe existant et préféré en créer un ex-nihilo pour que l'étymologie (basée sur l'action de compter, nepoa) soit parfaitement compréhensible

que la main pour le bras. L'index était un peu indiqué dans la gravure de Lorenzana, il occupe chez Clavijero une place bien plus prononcée. Surtout la position des autres doigts de la main a complètement été changée (le pouce touche le majeur). Clavijero aurait donc clairement inventé ce glyphe pour mieux exprimer l'idée de compter (mais pour une mentalité occidentale de son époque), par l'index levé et les autres doigts positionnés. C'est ce qu'il confirme dans son explicitation ${ }^{94}$. Ce faisant, Clavijero crée donc un glyphe toponymique nouveau et hybride, puisqu'il s'agit d'un glyphe adapté au lecteur européen.

En tout pour 16 glyphes toponymiques, Clavijero en aurait copié 14 de la version de Lorenzana (en en modifiant au moins deux), et pour cela il aura pioché dans 9 planches différentes ${ }^{95}$. Cinq planches sont utilisées pour un seul

94 F. Javier Clavijero, Historia antigua ..., págs. 286 : « 10. Una mano en actitud de contar con los dedos, para representar el pueblo de Necohualco (sic), que equivale a lugar donde se cuenta o de la numeración. » (lib. VII, Explicación..., Figuras de ciudades); (pág. 255 dans la l'édition originale).

${ }_{95} \quad$ 1. Messico $=$ pl. 25; 3 . Tollantzinco $=$ pl. 9 (non glosé $) ; 4$. Xochitzinco $=$ pl. $12 ; 5$. Huaxjacac $=$ pl. $24 ; 6$. Atotonilco $=$ pl. $9 ; 7$ Ahuilizapan $=$ pl. $26 ; \quad$ 8. Atenco $=$ pl. $29 ;$ 9. Tehuillojocan $=$ pl. 7 (non glosé); 11. Michmalojan = pl. 10; 12. Quauhtinchan $=$ pl. 22; 13. Tlacotepec $=$ pl. 12; 14. Macuilxochitl $=$ pl. 24; 15. Tlachco = pl. 10; 16. Tecozauhtla $=$ pl. 10. 
glyphe toponymique ${ }^{96}$. A trois occasions, deux glyphes proviennent d'une même planche (pl. 9, 12 et 24 de Lorenzana) ${ }^{97}$. Trois glyphes proviennent de la planche 10 (Xilotepec) $)^{98}$.

Plusieurs des glyphes copiés de l'édition de Lorenzana ne sont pas glosés dans celle-ci. Ils signaleraient donc l'effort soigné de recherche de la part de Clavijero pour les identifier (à partir des listes présentes dans l'édition de Purchas?). Ce travail de recherche a permis la constitution de la carte de l'Anahuac ou empire aztèque, en replaçant un à un le plus de villes tributaires consignées dans les 32 planches de la Matrícula imprimées par Lorenzana ${ }^{99}$.

Clavijero ajoute en fin volume une explication de ces figures de villes ${ }^{100}$.

\section{Costumes mexicas, armes et regalia dérivés de Gemelli Careri}

Beaucoup de spécialistes ont commenté les emprunts entre Clavijero et Gemelli Careri pour la copie du Mapa de Sigüenza ${ }^{101}$ ou de la roue calendaire ${ }^{102}$. Mais très peu se sont intéressés aux autres emprunts, moins connus, c'est pourquoi nous les regroupons ici. Ils tournent tous autour des gravures représentants les souverains préhispaniques, mexicanisés par Gemelli Careri, mais d'origine tezcocane en réalité. Au lieu de copies directes, il s'agit d'emprunts, ce qui explique sans doute leur identification plus difficile. On les retrouve dans la planche 20 de Clavijero consacrée aux costumes, dans les planches 7 et 11 pour des armes aztèques et dans la planche 22 pour un trône et un sceptre préhispaniques.

$96 \quad$ Pl. 7 (Quauhtitlan) pour le glyphe 9 Tehuillojocan (non glosé dans Lorenzana); pl. 22 (Tepeaca) pour le glyphe 12 Quauhtinchan (non glosé dans Lorenzana); pl. 25 (Xoconochco) pour le glyphe 1 rebaptisé Messico mais qui est Xoconochco; pl. 26 (Quauhtochco) pour le glyphe 7 Ahuilizpan; pl. 29 (Tlatlauhquitepec) pour le glyphe 8 Atenco (non glosé dans Lorenzana).

97 Glyphes 6. Atotonilco et 3. Tollantzinco pour la planche 9 Atotonilco. Glyphes 4. Xochitzinco et 13. Tlacotepec pour la planche 12 Toluca. (le second est glosé, pas le premier). Glyphes 5. Huaxjacac et 14. Macuilxochitl pour la planche 24 Coyolapan (aucun n'est glosé par Lorenzana).

$98 \quad$ Francisco Antonio de Lorenzana, op. cit., pl. 10 (Xilotepec). Les glyphes n ${ }^{\circ} 11$ Michmaloyan, 15 Tlachco et 16 Tecozauhtla. Michmaloyan est glosé, mais pas le dernier toponyme. Tlachco est glosé erronément Michmaloian.

99 ef. Jorge Cañizares-Esguerra, How to write de History of The New World, págs. 238, 241 et fig. 4-7 pág. 242.

100 F. Javier Clavijero, Storia Antica..., vol. 1, págs. 253'-255' (tome II, Spiegazione..., 4. Delle figure de Città); Historia antigua ..., págs. 285-286 (lib. VII, Explicación..., Figuras de ciudades).

101 María Castañeda de la Paz, «El largo periplo de un documento colonial : La Pintura de la Peregrinación de los culhuas-mexitin (El Mapa de Sigüenza) », págs. 628-632.

102 cf. Supra, partie I, note 14, pág. 309. 
La planche 20 de Clavijero représente six costumes mexicas (4 hommes et 2 femmes) pour représenter les couches sociales (plébeyens, nobles, soldat, prêtre).

Le 3e personnage (noble) reprend en petit des éléments d'une gravure de Gemelli Careri copiée du Codex Ixtlilxochitl et le 5e (soldat) pourrait aussi reprendre la gravure de soldat mexica publiée par Gemelli Careri ${ }^{104}$. Dans les deux cas il n’y a pas copie parfaite, mais récupération de plusieurs éléments caractéristiques. Là encore, cela est très révélateur de la méthode de travail de Clavijero dans son rapport aux éditions de codex qui l'ont précédé.

La concordance entre le portrait d'un noble (pl. 21, 3e case «Un Nobile ») et la gravure de Gemelli Careri copiant un des portraits de plain-pied du Codex Ixtlilxochitl est visible par le contour de la cape à la frange crénelée surmontée d'une bordure blanche à petits cercles (Clavijero) ou grands cercles plus ou moins ovales (Gemelli Careri). Mais les attitudes des bras et jambes ne concordent pas exactement et dans les deux cas le décor de plumes des coiffes a été gommé par Clavijero.

Le portrait de Tocuepotzin (Codex Ixtlilxochitl, f. 105r.), que Gemelli Careri renomme Quauhtimoc ${ }^{105}$, n'a pas la même attitude. Au premier regard la position des bras et mains, des pieds et des jambes et les objets tenus ne correspondent pas. Là où le noble de la planche de Clavijero a le genou gauche légèrement fléchi du fait de son pied posé sur une pierre, la gravure du pseudo Quauhtimoc (Tocuepotzin) de Gemelli Careri a les deux pieds au sol. La différence la plus importante reste la main gauche, qui est tournée vers l'intérieur sans rien tenir chez Clavijero, et vers l'extérieur tenant un calumet (acayetl) et un bouquet de fleurs (xochitl) chez Gemelli Careri.

Le portrait de Nezahualpilli (Codex Ixtlilxochitl, f. 108r.), que Gemelli Careri renomme Ticocic (pour Tizoc) ${ }^{106}$, est un peu plus proche (cf. fig. 5). Si on prend en compte la possible inversion d'une gravure à l'autre, l'attitude du bras gauche et de la jambe droite ne concordent pas, mais celle du bras droit et de la jambe gauche sont assez proches. Reste que l'objet en plumes (bouquet ou chasse-mouche) n'a pas du tout la même forme (dans les gravures de Gemelli

103 F. Javier Clavijero, Storia Antica..., vol. 1, pág. 224' bis (tome II, lib. VII).

104 Éléments signalés par Geert Bastiaan van Doesburg, Códice Ixlilxochitl. Apuntaciones y pinturas de un historiador. Estudio de un documento colonial que trata del calendario naua, Mexico, FCE, ADV, 1996, págs. 33-35.

105 G.F. Gemelli Careri, Viaje a la Nueva España, pág. 29 (1699, vol. 6, fig. 4, pág. 50).

106 G.F. Gemelli Careri, Viaje a la Nueva España, pág. 29. Ces changements de noms permettent à Careri de constituer artificiellement une galerie de portraits de souverains de Mexico Tenochtitlan : mais aucun d'entre eux n'est réellement mexica ou tenochca. 

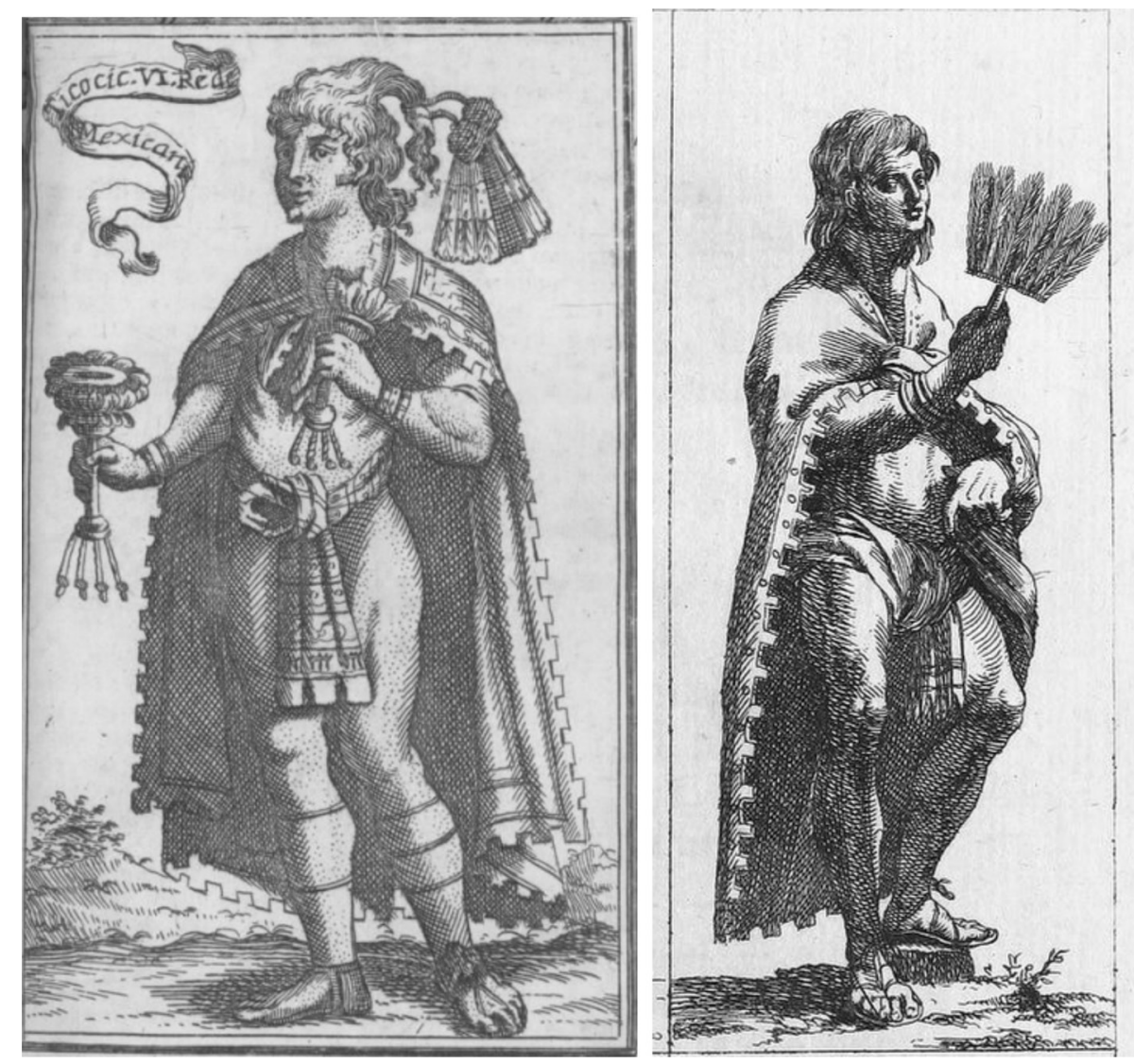

Figure 5 : représentation de Nezahualpilli, souverain de Tezcoco (renommé Tizocic par Careri pour en faire un souverain de Mexico Tenochtitlan) (édition de 1728) et représentation d'un noble aztèque par Clavijero (pl. 20, 1780)

Careri il est doté d'éléments inférieurs totalement absents chez Clavijero), et surtout que les franges crénelées de la cape se détachent vers l'intérieur (côté senestre) chez Clavijero et vers l'extérieur (des deux côtés) chez Gemelli Careri. Le pli que fait la cape a également disparu chez Clavijero. Enfin le nœud et la forme du pagne ont également changé. Au total un faisceau de divergences et de convergences entre les deux gravures ne permet pas de conclure à une copie, mais à de possibles emprunts par le graveur (sur instruction de Clavijero).

Il en va de même avec la gravure d'un soldat (pl. 21, 5e case «Un Soldato ») par Clavijero, très certainement inspirée de celle du « Soldato mesica 

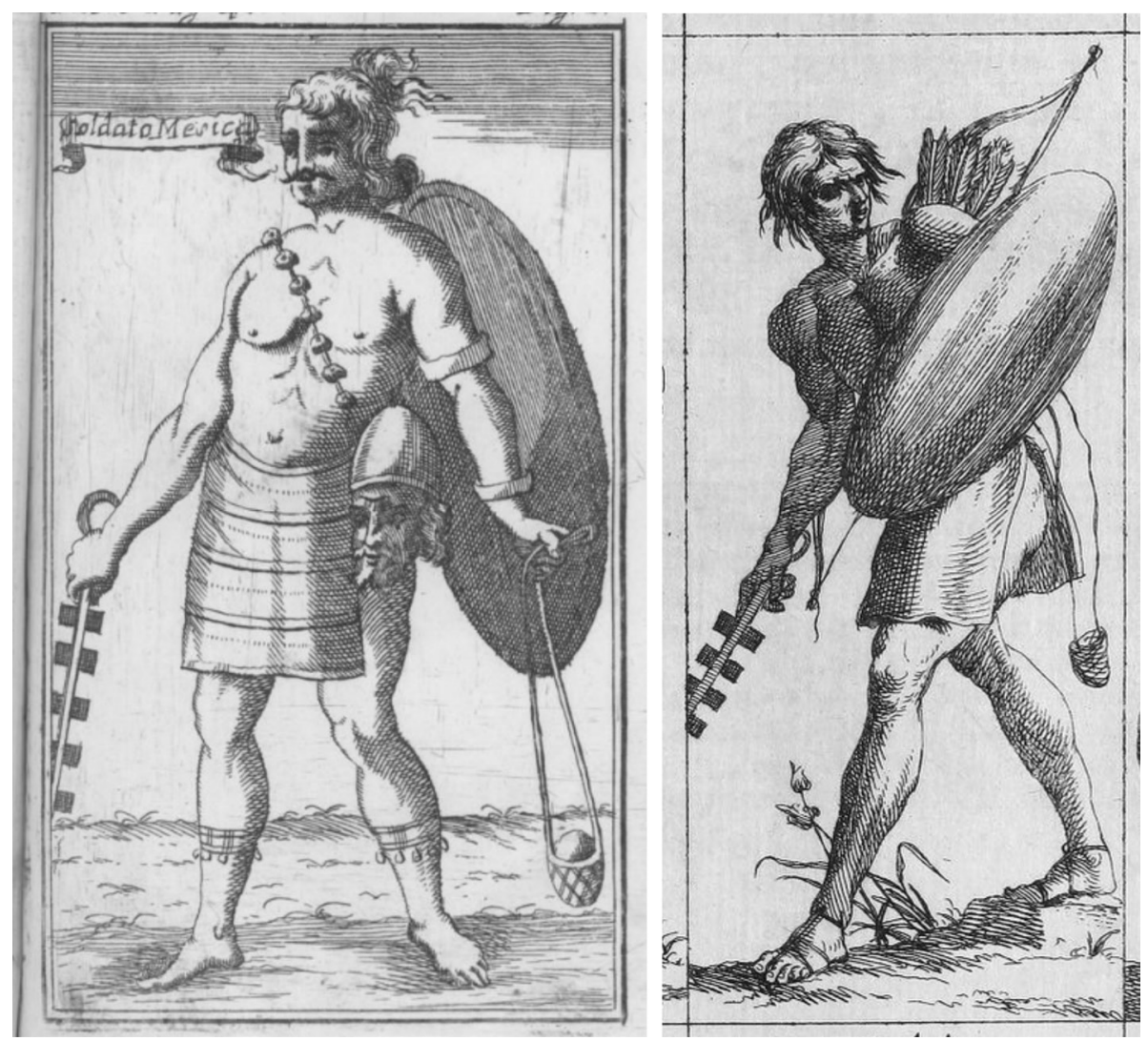

Figure 6 : représentation de Tzontecomatl, fondateur de la province acolhua (renommé «soldat mexica» par Careri) (édition de 1728) et représentation d'un soldat mexica par Clavijero (pl. 20, 1780). Si l'attitude change et plusieurs éléments de 1728 disparaissent, en revanche d'autres sont repris (forme ovale du bouclier, format atypique du pagne, fronde, maquahuitl)

(sic) » de Gemelli Careri ${ }^{107}$ (cf. fig. 6). La position du bouclier est totalement incompatible, puisqu'on en voit le dessus chez Clavijero et le dessous chez Gemelli Careri. De même le soldat de Clavijero est doté d'un arc et d'un carquois de flèches, totalement absents chez Gemelli Careri, et la position du torse, du bras gauche et des jambes n'est pas la même. Mais on repère plusieurs éléments communs :

107 G.F. Gemelli Careri, Viaje a la Nueva España, pág. 61 (1699, vol. 6 fig. 2, pág. 48 « Soldato Mesica »). Lorenzo Boturini l'a identifié comme Tzontecomama. Il correspondrait en réalité au fondateur de la région acolhua, Tzontecomatl. cf. Patrick Lessre, « Illustrations acolhua de facture européenne ? (Codex Ixtlilxochitl, ff. 105-112) », Journal de la Société des Américanistes, n 84-2, 1998, págs. 109-110. 
- la forme ovale du bouclier, élément inédit dans les gravures qui copient le Codex Mendoza ou la Matrícula de Tributos;

- l'épée ou maquahuitl avec l'extrémité de son manche trouée, et ses lames d'obsidienne totalement déformées;

— la fronde du côté droit, même si elle n'a plus de projectile;

- la forme atypique du pagne qui ressemble plutôt à un tablier quadrangulaire.

Certes, la tête décapitée, le collier d'oreilles, les ornements de jambes, l'absence de sandales ou le toupet de cheveux présents dans la gravure de Gemelli Careri de 1699, ne sont pas repris chez Clavijero. Mais les éléments communs et surtout leur taille ou forme, souvent atypiques, nous semblent révélateur d'emprunts à cette gravure par l'artiste travaillant pour Clavijero et selon ses instructions.

Armes Prénispaniques ou regalia (Planches 11, 7 et 22) :

Si les emprunts au Codex Ixtlilxochitl par le biais des gravures de Gemelli Careri ne sont pas totalement concordants pour les portraits de noble et de soldat, il n'en va pas de même pour la planche 11 concernant les éléments militaires ${ }^{108}$. Le 3e bouclier est ovale et atypique, tout comme le maquahuitl ("Spada messicana ») totalement déformé pour les lames d'obsidienne, mais dont le manche troué avec une attache est correct (le trou étant simplement fortement exagéré). Ce sont deux emprunts directs à la gravure du soldat mexicain par Gemelli Careri ${ }^{109}$. La forme du bouclier ovale et surtout le fait de voir l'envers d'un bouclier aztèque, avec ses deux attaches caractéristiques, sont totalement absents de la Matrícula de tributos (Lorenzana 1770) ou du Codex Mendoza (édité par Purchas en 1625). On retrouve ces deux éléments (bouclier ovale, maquahuitl déformé) mis en situation lors d'un simulacre de combat dans la planche 7 de Clavijero (sacrifice dit 'gladiatorial') ${ }^{110}$.

108 F. Javier Clavijero, Storia Antica..., vol. 1, pág. 150’ (tome II, lib. VI) pour les deux éléments regroupés sous l'intitulé «Spada messicana ». Les boucliers traditionnels ont déjà été analysés en partie II, 2. cf. Supra, págs. 312-313.

109 G.F. Gemeldi Careri, Viaje a la Nueva España, pág. 61 (1699, vol. 6 fig. 2, pág. 48 « Soldato Mesica»).

110 F. Javier Clavijero, Storia Antica..., vol. 1, pág. 48’ (tome II, lib. VI) : « il Sacrifizio gladiatorio ». Mais l'anneau du maquahuitl à senestre est transformé en crochet. Les pagnes sont totalement occidentalisés, tout comme la coiffe de plumes et l'architecture coloniale en arrière-plan (avec œil-de-bœuf et grandes fenêtres grillagées). 

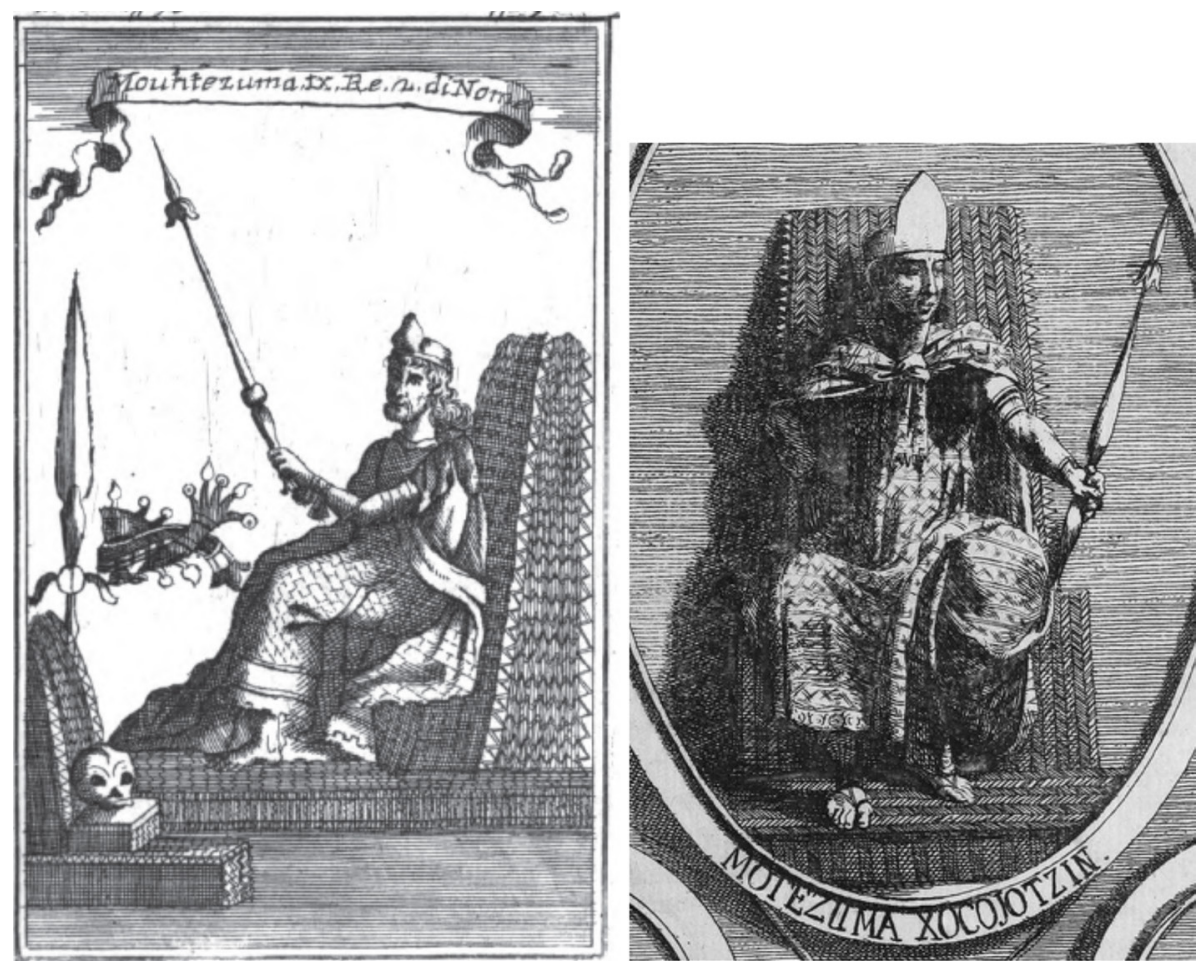

Figure 7 : représentation de Nezahualpilli rendant la justice (renommé Moctezuma 9e roi [de Mexico Tenochtitlan] par Carreri) (édition de 1728). Réemploi par Clavijero (détail de la pl. 22, 1780) pour représenter le «dernier» souverain aztèque

Enfin, la dernière planche de l'oeuvre (représentant Moctezuma entouré par les médaillons de quatre conquistadors) ${ }^{111}$ reprend également une gravure de Gemelli Careri ${ }^{112}$ mais adaptée de façon très intelligente (cf. Fig. 7) : Moctezuma Xocoyotzin assis sur son « trône » (tepotzoicpalli) est une adaptation de $\mathrm{Ne}$ zahualpilli rendant la justice de Carreri (renommé Moctezuma 9e roi [de Mexico Tenochtitlan], ce qui a sans doute facilité son remploi par Clavijero). Le premier est de face tandis que le second est de profil. On reconnaît le même "trône » (tepotzoicpalli) déformé : le siège a été rehaussé (alors qu'il est beaucoup plus bas normalement) et le dossier est dentelé sur les côtés. Surtout les deux souverains

111 F. Javier Clavijero, Storia Antica..., vol. 2, pág. 8' (tome III, lib. VIII).

112 G.F. Gemeldi Careri, Viaje a la Nueva España, pág. 41. Loriginal du Codex Itlilxochitl a été perdu mais correspond en réalité au roi de Tezcoco Nezahualpilli rendant la justice. cf. Patrick LesBre, « Nezahualpilli administrant la justice », Histoire et société en Amérique Latine, Aleph, n 11, Paris, 2001, págs. 85-106. Cette gravure a déjà été utilisée par Clavijero pour les glyphes terre et eau de la planche 15 (éléments H et I). cf. Supra, pág. 317. 
tiennent en main le même « sceptre » étrange à fleur de lys (celui de Moctezuma étant renflé sur le bas et la partie supérieure de la main). Du coup on comprend que le vêtement a été également librement inspiré de la gravure de Gemelli Carreri (tunique et cape couvrant le corps à l'exception des bras), tout comme la « couronne " triangulaire (xihuitzolli). Clavijero prolonge près d'un siècle après Gemelli Careri son usurpation de l'avant-dernier souverain de Tezcoco renommé Moctezuma. La liberté de réemploi n'est probablement pas que le fait de l'artiste : le choix vient de Clavijero, soucieux de trouver une gravure permettant une représentation correcte de la royauté préhispanique. Mais la planche originale (perdue) correspond à une reconstruction tezcocane de la fin du Xvie siècle.

On voit ainsi comment Clavijero, et le graveur à qui il a confié la réalisation des planches illustratives de son ouvrage, piochent dans différentes reproductions de codex déjà existantes (Purchas 1625, Gemelli Careri 1699, Lorenzana 1770) pour en élaborer quelque chose de nouveau et de didactique. Avec parfois quelques surprises entre le choix de scènes ou éléments de codex pourtant publiés qui sont délaissés au profit de gravures de chroniqueurs moins fiables. Mais aussi av ec une liberté d'emploi très intéressante pour les éléments empruntés à Gemelli Carreri ou pour les glyphes toponymiques resémantisés par Clavijero quitte à les changer.

\section{Gravures plus ou moins scientifiques}

D'autres gravures de l'ouvrage de Clavijero (planches 4 à 7 pour la religion, planches 18-19 pour la vie quotidienne) proposent une reconstitution du passé aztèque qui se veut sérieuse, mais se base parfois sur des sources du XVIe ou XVIII siècles déjà fantaisistes (gravure du Grand Temple par Ramusio ou Diego Valadès, Ramusio ou Kircher). Clavijero ne peut pas les corriger faute d'accès aux originaux conservés au Mexique (Codex Ixtlilxochitl, collection Boturini) ou en Espagne. Les pyramides du Codex Mendoza publié par Purchas en 1625 n'ont pas attiré suffisamment l'attention de Clavijero. Et manifestement il n'a pas eu accès au Codex Magliabechi, ni au Codex de Florence, pourtant tout deux conservés en Italie.

\section{Scènes de LA VIE QUOTIDIENNe PluS OU MOINS FIDÈLES :}

Deux planches reprennent des éléments de la vie quotidienne : la façon de fabriquer le plain, assez fidèle, et le temazcal ou bain de vapeur aztèque, totalement erroné dans son architecture. 
Rien à voir avec la scène d'éducation de jeune fille du Codex Mendoza (f. 60r., niveau 3). La scène a été pourtant inclue dans les gravures de Purchas de $1625^{114}$. Mais il semble que Clavijero ait opté pour une scène plus réaliste, car c'est une tradition encore en vigueur à l'époque où il rédige. Sa version est totalement occidentalisée.

Elle semble reprendre un détail de la gravure du Grand Temple de fr. Diego Valadés ${ }^{115}$, dans laquelle on voit trois femmes s'activer pour faire des tortillas (l'une égraine le maïs dans un récipient, l'autre le moud sur un metate, la troisième - à l'arrière-fond- façonne et cuit les galettes sur un comal). On retrouve les mêmes gestes et les mêmes instruments ${ }^{116}$, la même distribution et répartition des rôles, mais le metate est horizontal, très peu relevé). Ce dernier détail permet de rejeter Valadés comme source au profit de Benzoni (cf. fig. 8), qui contient dès 1565 une scène similaire avec trois Indiennes faisant les mêmes gestes (qui a inspiré Valadés) : le metate y est incurvé plus correctement et
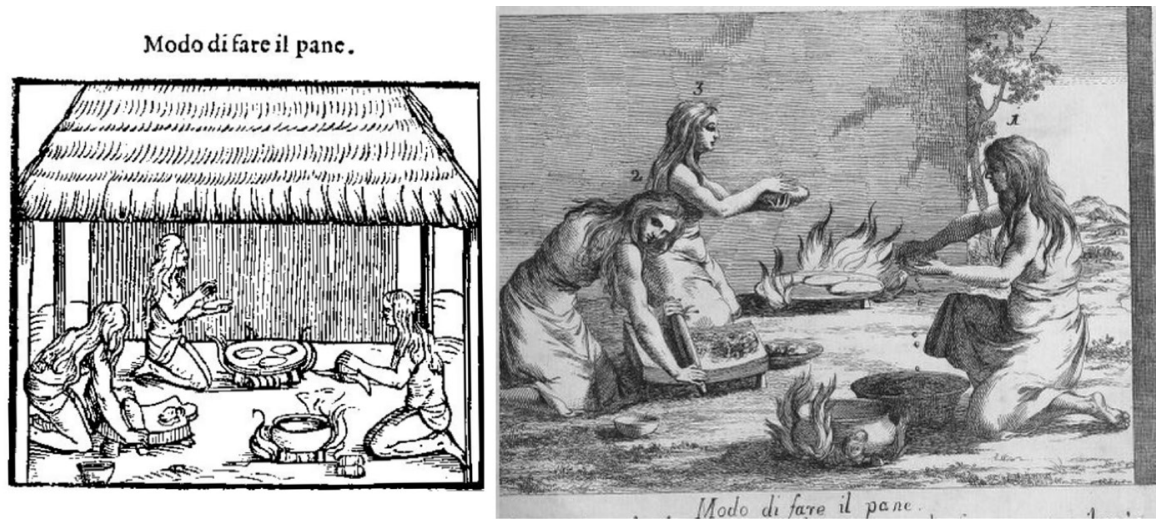

Figure 8 : fabrication des galettes de maïs représentée par Girolamo Benzoni (Modo di fare el pane, édition de 1565) et reprise pour l'ouvrage de Clavijero (pl. 18, 1780)

\footnotetext{
113 F. Javier Clavijero, Storia Antica..., vol. 1, pág. 218' (tome II, lib. VII).

114 Samuel Purchas, Hakluytus Posthumus..., pág. 1106 éducation (éléments Aa, Bb, Ff, Ee dans la gravure).

115 Fr. Diego Valadés, Retórica Cristiana, p.[389] (pág. 171' de l'édition originale en latin : « Tipus sacrificorum que in maniter indi faciebant in Novo Indiarum orbe precipue in Mexico »). Ces trois femmes font pendant à trois autres à dextre du Grand Temple qui elles s'activent pour faire du pulque.

116 On voit bien trois galettes sur le comal dans les deux gravures. La troisième femme a simplement une bassine en plus dans laquelle elle fait tomber les grains du maïs qu'elle égrène, détails absents de la gravure de Valadès, et donc apports propres à Clavijero.
} 
l'attitude de la femme du milieu (qui fait cuire les galettes) est plus proche ${ }^{117}$. Surtout la légende est exactement la même. On observe donc que Clavijero a préféré suivre une version plus ancienne, celle de Benzoni (1565). Et surtout qu'il a resémantisé la scène en changeant le travail de la première femme, qui, désormais, égraine le maïs, alors qu'auparavant elle cuisinait (euphémisme qui occulte le fait qu'on ne parvient pas vraiment à identifier son action tant dans Benzoni que dans Valadés). On voit distinctement les grains tomber dans un récipient dans la planche de l'ouvrage de Clavijero.

Tezmacal (ll Temazcalli, o sia ipocausto messicano, Planche 19) ${ }^{118}$

La planche se veut scientifique en nommant le bâtiment hypocauste (terme employé pour les thermes romains) ${ }^{119}$ plutôt que bain de vapeur, et en en donnant trois vues différentes : arrière (avec four), avant (avec entrée) et coupe de l'édifice ${ }^{120}$. Mais la représentation est totalement erronée car elle propose une sorte d'igloo de pierre : l'édifice est circulaire et la coupe le montre avec une voute, chose impossible pour l'époque préhispanique, tout comme la porte d'entrée voutée de l'édifice. Peut-être cela correspond plus à ce que Clavijero a éventuellement vu au Mexique à son époque. Mais cette représentation n'a rien à voir avec celle d'un bain de vapeur (temazcal) du Codex Magliabechi, pourtant conservé en Italie ${ }^{121}$.

La planche est assortie à l'époque puisqu'on inclut un éphèbe totalement nu de dos allongé sur une sorte de banquette à l'intérieur du bain de vapeur. Cela sert à donner une échelle à préciser l'usage et à romaniser les Aztèques.

\section{Grand Temple de Mexico (IL Tempio maggior di Messico, planche 4) ${ }^{122}$}

Clavijero, tout en utilisant fortement l'édition de Lorenzana pour les glyphes de vêtements militaires, de villes ou de boucliers, ne reprend pas la planche

117 Girolamo Benzoni, Historia del mondo nuovo, 1565, fol 56v Modo di fare il pane. En ligne sur le site de la Biblioteca Nacional de España : http ://bdh-rd.bne.es/viewer.vm?id=0000014320\&page=1 [consulté le 9 juillet 2019].

118 F. Javier Clavijero, Storia Antica..., vol. 1, pág. 224' (tome II, lib. VII).

119 Paul Robert, Dictionnaire alphabétique et analogique de la lange française, Paris, Le Robert, 1972, tome III, pág. 562 : « hypocauste [...] Fourneau souterrain pour chauffer les bains, les chambres (dans les thermes, etc.). »

120 Le tout est spécificé par trois légendes : « 1 La parte dinanzi. 2 La parte di dietro. 3 Spaccato » F. Javier Clavijero, Storia Antica..., vol. 1, pág. 224' (tome II, lib. VII).

121 Codex Magliabechi, f. 77r : l'édifice principal est quadrangulaire, avec la représentation d'une divinité féminine au-dessus de l'entrée. Il dispose d'un four mais aussi d'un bassin extérieur pour l'eau usagée.

122 F. Javier Clavijero, Storia Antica..., vol. 1, pág. 26’ (tome II, lib. VI). 
dans laquelle le Grand Temple de Mexico est réinventé ou rêvé à partir des descriptions des chroniqueurs. S'il écarte avec raison cette grande tour sans degrés intermédiaires, avec deux sanctuaires totalement fantaisistes et une rambarde entourant la partie sommitale (cf. fig. 12) ${ }^{123}$, il propose cependant une version tout aussi fautive.

Sa planche (cf. fig. 9) représente une sorte de ziggurat meso-américaine du fait d'une mauvaise compréhension des escaliers, mais aussi de l'espace supérieur, où la pierre de sacrifice (forme erronée) est bien trop éloignée des sanctuaires, lesquels sont réduits à deux tours ou " clochers » malgré les représentations de temples préhispaniques du Codex Mendoza (gravures de Purchas) ${ }^{124}$. Son modèle semble être la gravure du texte du Conquistador anonyme ${ }^{125}$, qui a la même disposition pour les escaliers en ziggurat, et les mêmes deux sanctuaires semblables à des clochers verticaux avec porte d'entrée voûtée, étage à arcades et toits en pente (totalement improbables pour l'architecture préhispanique). Seule la pyramide en briques ou pierres à cinq corps est à peu près correcte. Clavijero a manifestement repris tous ces éléments mais agrandi démesurément l'esplanade sommitale (en y ajoutant une pierre de sacrifice erronée). Du coup les sanctuaires sont espacés au lieu d'être accolés. Il a également disposé les escaliers différemment (sur la gauche de la façade principale de la pyramide alors que la gravure du Conquistador anonyme les mettait sur le côté droit) et a changé l'orientation de l'édifice, dont on voit le côté gauche et non le côté droit (sans doute du fait de l'inversion produite par la copie d'une gravure).

${ }^{123}$ Francisco Antonio de Lorenzana, Historia de Nueva-España..., pl. El Grande Templo de México (gravure en double page, placée avant le chapitre Advertencias para la inteligencia de las Cartas de Hernán Cortés). La version de Lorenzana, pour ce qui est de la forme du Grand Temple, provient des pyramides aztèques inventées par I. A. Schwebel, gravure de Nuremberg de 1685, modèle diffusé ensuite par Bernard Picard en 1722. cf. Electra y Tonatiuh Gutiérrez, Visión Europea del Templo Mayor de Tenochtitlan, Mexico, 1982, planches 6 et 12. Ces gravures ont inspiré un tableau colonial représentant la conversion des Indiens à l'époque de la conquête : José Vivar y Valderrama, La consagración de los templos paganos y la primera misa en México-Tenochtitlan (MUNAL). cf. Los pinceles de la historia. El origen del Reino de la Nueva España 1680-1750, Mexico, MUNAL, 1999, pág. 162.

Jorge Cañizares a signalé comment Clavijero avait rejeté cette école historique pour le choix de gravure de son Grand Temple de Mexico. cf. Jorge Cañizares-Esguerra, How to write de History of The New World, pág. 238 et figure 4.6 pág. 240.

124 On remarquera au passage que si Lorenzana n'avait pas compris l'existence de degrés pour les pyramides aztèques (chose que corrige Clavijero puisque son édifice en comporte cinq), en revanche il avait tout à fait raison pour l'escalier d'une seule volée en façade. Simplement celui-ci était double au lieu d'être unique. Sa représentation de pierre de sacrifice est également meilleure que celle de Clavijero.

125 El Conquistador anónimo, Mexico, Editorial América, 1941, pág. 35. Publié pour la première en 1556 par Giovanni Battista Ramusio à qui on attribue cette gravure. Ces filiations possibles ont été étudiées par Jorge Cañizares. cf. Jorge CañIZares-Esguerra, How to write de History of The New World, pág. 238 et fig. 4-5 pág. 239. 

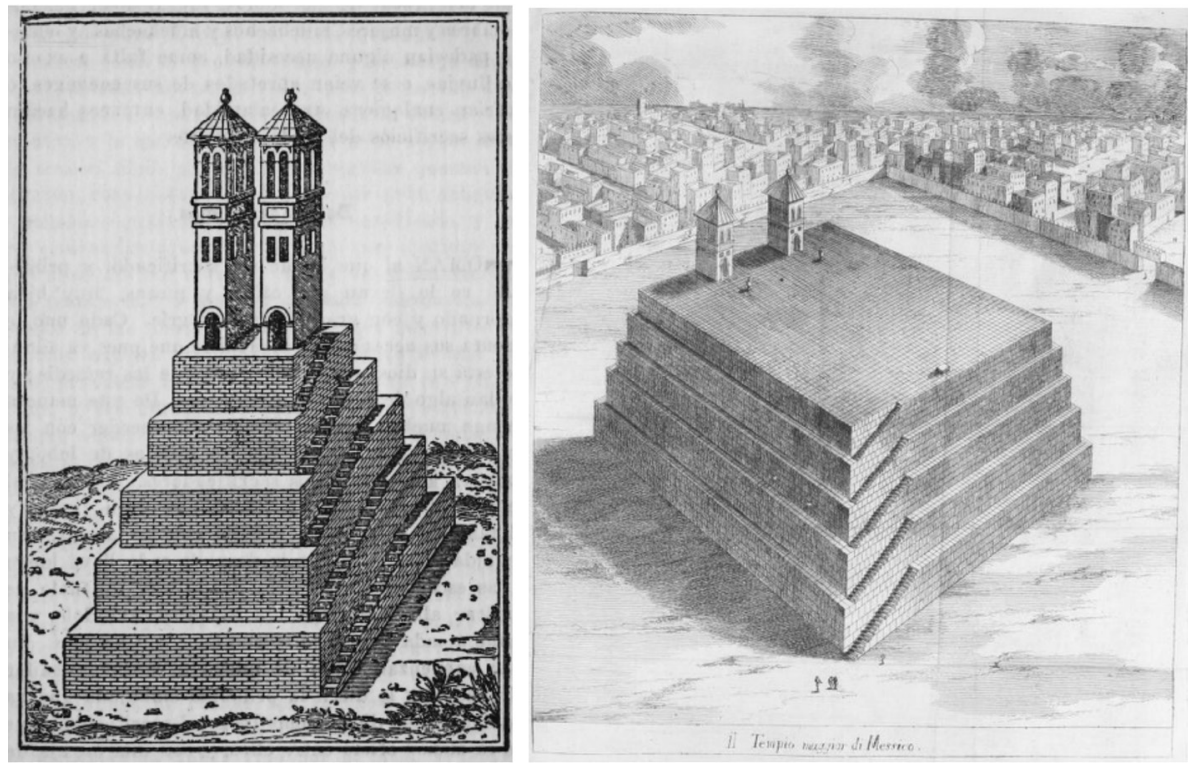

Figure 9 : représentation du Grand Temple de Mexico dans la version publiée en 1556 par G.B. Ramusio du Conquistadore anonyme (édition de 1941), reprise et «améliorée» dans l'édition de Clavijero (planche 4, 1780)

Cela témoigne de l'incompréhension manifeste des pyramides aztèques du fait de l'inexistence de fouilles archéologiques (Santa Cecilia Acatitlan), ou de la non connaissance de la planche du Templo Mayor (folio 112v du Codex Ixtlilxochitl). En effet, le folio 112v est une représentation du Grand Temple de Tezcoco (longtemps prise, suite à la copie donnée par Veytia, pour celui de Mexico Tenochtitlan) en grand format ${ }^{126}$.

Manifestement Clavijero n'a pas vu ce folio du Codex Ixtlilxochitl, pourtant présent à Mexico à l'époque, suite à la confiscation de la collection Boturini. Et, avant son expulsion de Nouvelle-Espagne, il n'a manifestement pas vu non plus de pyramide aztèque encore conservée suffisamment correctement pour l'inciter à ne pas représenter les escaliers de la façon dont il le fait.

Il lui restait encore la possibilité de reprendre les gravures du Codex Mendoza éditées par Purchas en 1625, notamment celle concernant les conquêtes

126 Il comprend une représentation détaillée de l'architecture, avec le grand escalier double en façade et ses rampes, mais aussi la forme des deux sanctuaires au sommet. Les deux sanctuaires sont encore traditionnels dans leur forme, avec le décor de leur façade et les crêtes faitières. Ils sont aussi voisins, se touchant à leur base, détail qui fut confirmé par les fouilles du Templo Mayor de Mexico en 1978. Seule manque la pierre de sacrifice et le Chac-mol, subtilement censurés. 
d'Axayacatl. Mais il joue de malchance car Purchas n'a pas repris la représentation en grand format du grand temple de Tlatelolco avec le suicide de Moquihuix. Loriginal, conservé à Oxford, (folio 10r), montre parfaitement un grand escalier double avec ses rampes en façade, les façades des sanctuaires et leur décor (sans crête faitière), sur une pyramide à 6 étages et une base additionnelle. La gravure de Purchas ne reprend que la durée du règne d'Axayacatl, sa représentation et le symbole de guerre ${ }^{127}$, mais aucune des conquêtes, contrairement à Moctezuma Ilhuicamina ${ }^{128}$. Cependant d'autres pyramides préhispaniques sont correctement représentées dans les gravures de Purchas (cf. fig. 11).

Celles de la 3e partie du Codex Mendoza reprennent la représentation de profil de deux pyramides, avec un grand escalier sur la façade. C'est le cas du folio sur l'apprentissage des prêtres ${ }^{129}$, et de celui sur l'apprentissage des soldats ${ }^{130}$. Ou bien l'une des conquêtes de Moctezuma Ilhuicamina reproduite en gravure par Purchas, Quiyauhteopan, représente également une pyramide sans sanctuaire au sommet, mais avec un escalier unique courant d'une seule volée sur la façade de la pyramide ${ }^{131}$. On trouve une pyramide complète reproduite parmi les conquêtes d'Izcoatl, avec un même escalier d'une seule volée, rampe, et sanctuaire au sommet (simplifié en glyphe de maison à toit de chaume) pour Teocalhueyacan ${ }^{132}$. Enfin et surtout, la première province tributaire reprise par Purchas inclut la représentation d'une pyramide avec un sanctuaire dont le décor traditionnel est correct (frise de cercles blancs sur fond noir au-dessus du linteau d'entrée) $)^{133}$. Alors que Clavijero a manifestement suivi l'impression du Codex Mendoza de 1625 (pour les noms des souverains mexica par exemple), comment expliquer qu'il n'ait pas tenu compte des pyramides encore correctement représentées et qu'il ait commis cette bourde majeure avec la planche 4 ?

Il semble en fait dépendre plus de l'édition de Lorenzana, déjà passablement déformée dans le goût du xvIIIe siècle. Cependant seule la province tribu-

127 Samuel Purchas, Hakluytus Posthumus..., pág. 1076.

128 Samuel Purchas, Hakluytus Posthumus..., pág. 1075.

129 Samuel Purchas, Hakluytus Posthumus..., pág. 1109 (chap. 7, § 3 Exercises of Priests. Punishments used in Mexico). La partie inférieure reprend une pyramide complète de profil dans l'angle inférieur droit (élément $\mathrm{X}$ dans la gravure). Si le sanctuaire est remplacé par le glyphe calli, et les corps de la pyramide sont déformés par la gravure, la position de l'escalier sur la façade, en un seul corps, ne fait aucun doute.

130 Samuel Purchas, Hakluytus Posthumus..., pág. 1110. La pyramide de profil avec un grand escalier sur la façade est parfaitement visible sur la seconde ligne (élément G dans la gravure de Purchas).

131 Samuel Purchas, Hakluytus Posthumus..., pág. 1075 (Chap. 7, \& 1 Mexican Pictures, or Historic without Letters).

132 Samuel Purchas, Hakluytus Posthumus..., pág. 1069 Teocalhueyacan (scène D dans la gravure) (Lib. V, chap. Mexican historie in pictures. Chronicle without writing. Yzcoatçi).

133 Samuel Purchas, Hakluytus Posthumus..., pág. 1080 Huiznahuac (scène A dans la gravure) (Lib. V, chap. Mexican historie in pictures. Chronicle without writing. Yzcoatçi). 
Fig. 10 : Représentations correctes de pyramides aztèques dans la copie du Codex Mendoza publiée par Purchas en 1625

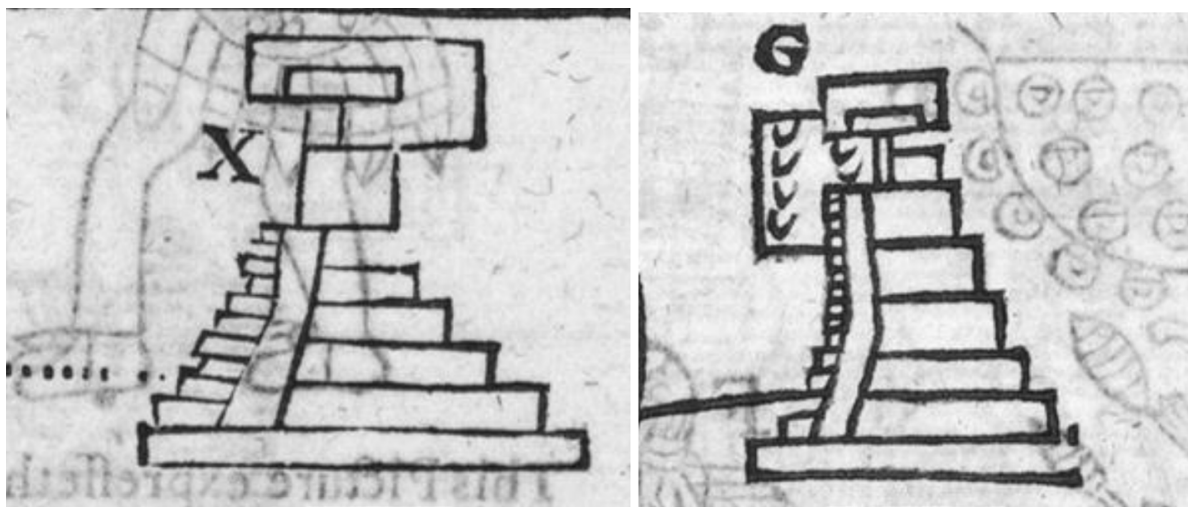

Pyramide aztèque représentée correctement (mais sanctuaire schématique) pour l'apprentissage des prêtres (Purchas pág. 1109), et l'apprentissage des soldats (Purchas pág. 1110)
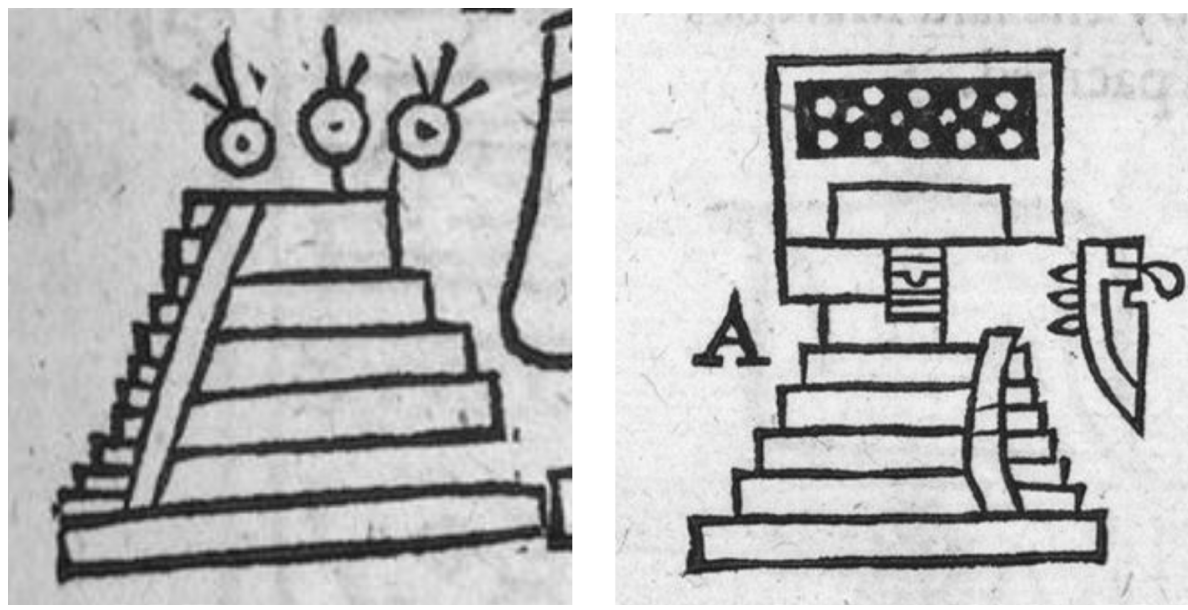

Pyramide aztèque représentée correctement sans sanctuaire : glyphe de Quiyauhteopan (Purchas pág. 1075); Pyramide et sanctuaire aztèques corrects : province tributaire de Huiznahuac (Purchas pág. 1080)

taire de Quauhnahuac dans l'édition de Lorenzana comporte un glyphe toponymique avec une représentation presque exacte d'une pyramide préhispanique (Tezcalizmic $)^{134}$, tout comme la province de Tollocan, ou la province de Tlapan.

134 Francisco Antonio de Lorenzana, Historia de Nueva-España..., pl. 5 (Quauhnahuac). Le glyphe représente une pyramide avec 4 degrés et une plateforme de base, un grand escalier d'une seule volée sur le 
Fig. 11 : Représentations incorrectes de pyramides aztèques dans la copie de la Matrícula de Tributos publiée par Lorenzana en 1770
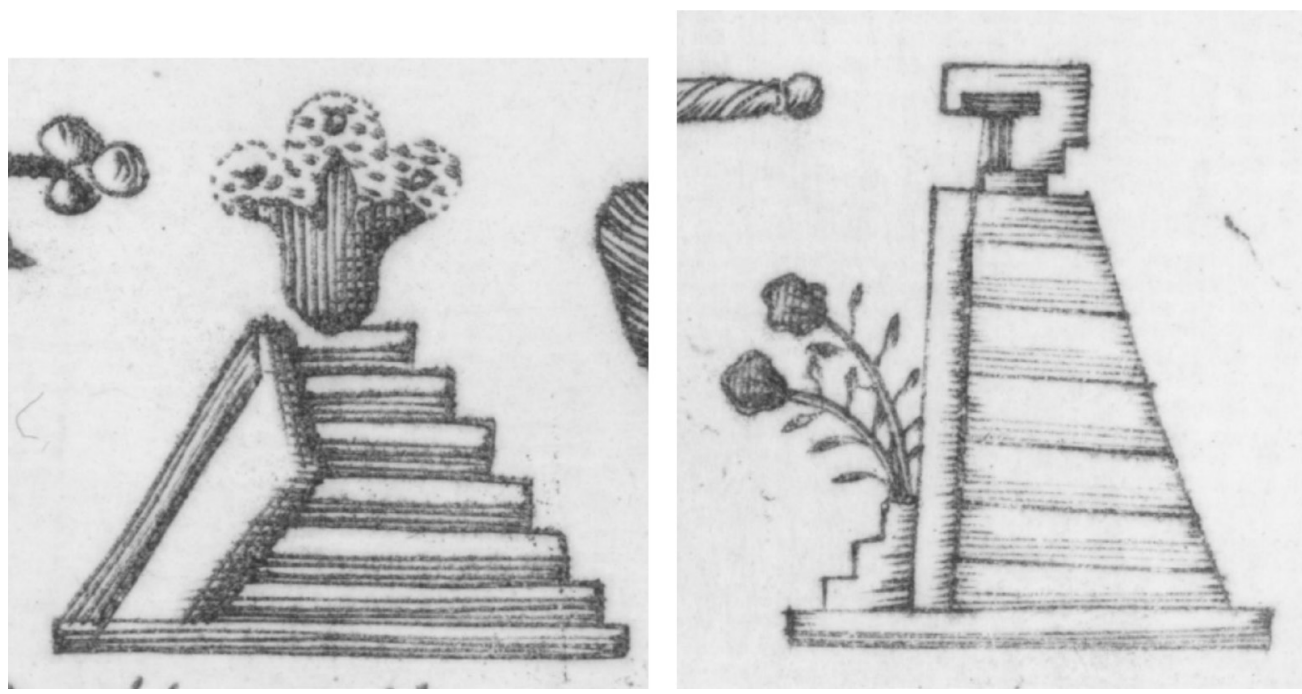

Pyramide aztèque erronée du fait d'un escalier totalement déformé : [Ichcateopan] province de Tlapan (Lorenzana, pl. 19) et [Capulteopan] province de Tollocan (Lorenzana, pl.12)
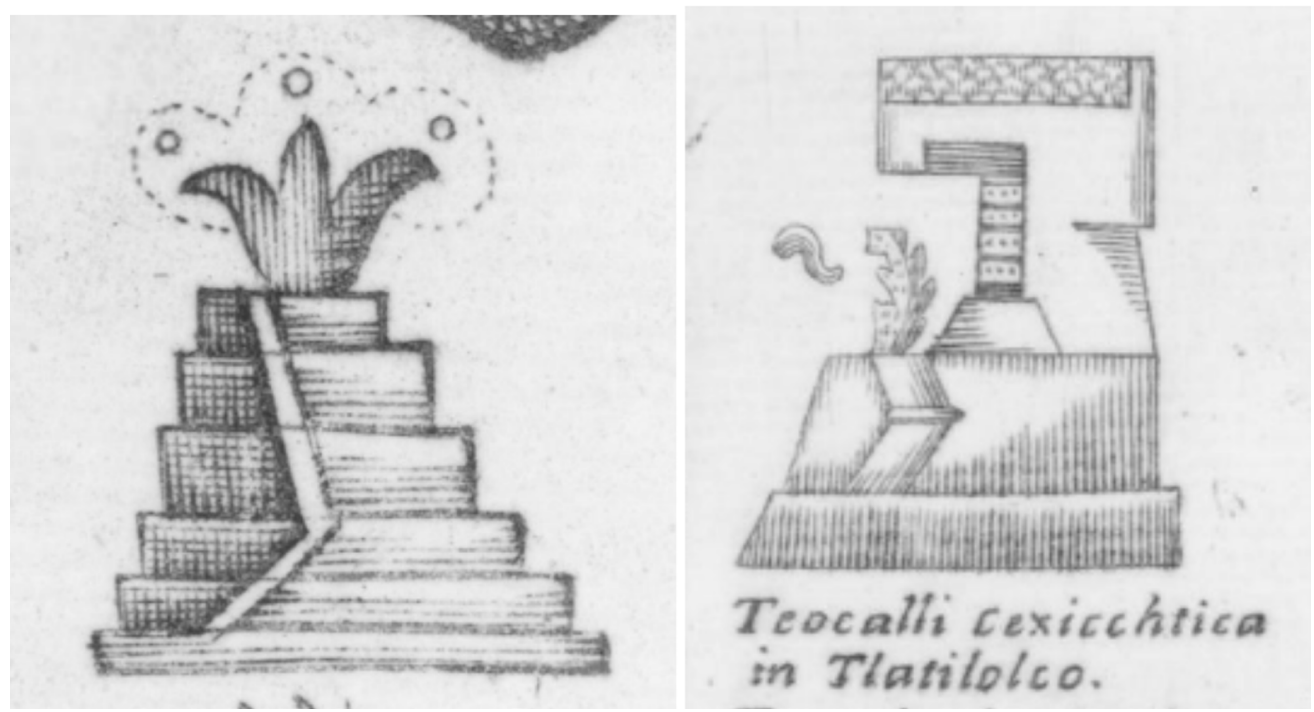

Pyramides aztèques inexactes : confusion entre marches et degrés de la pyramide (glyphe d'Ichcateopan : province de Tepequacuilco: Lorenzana, pl. 17); absence d'indication de marches et de degrés (province de Tlatelolco : Lorenzana, pl. 2) 


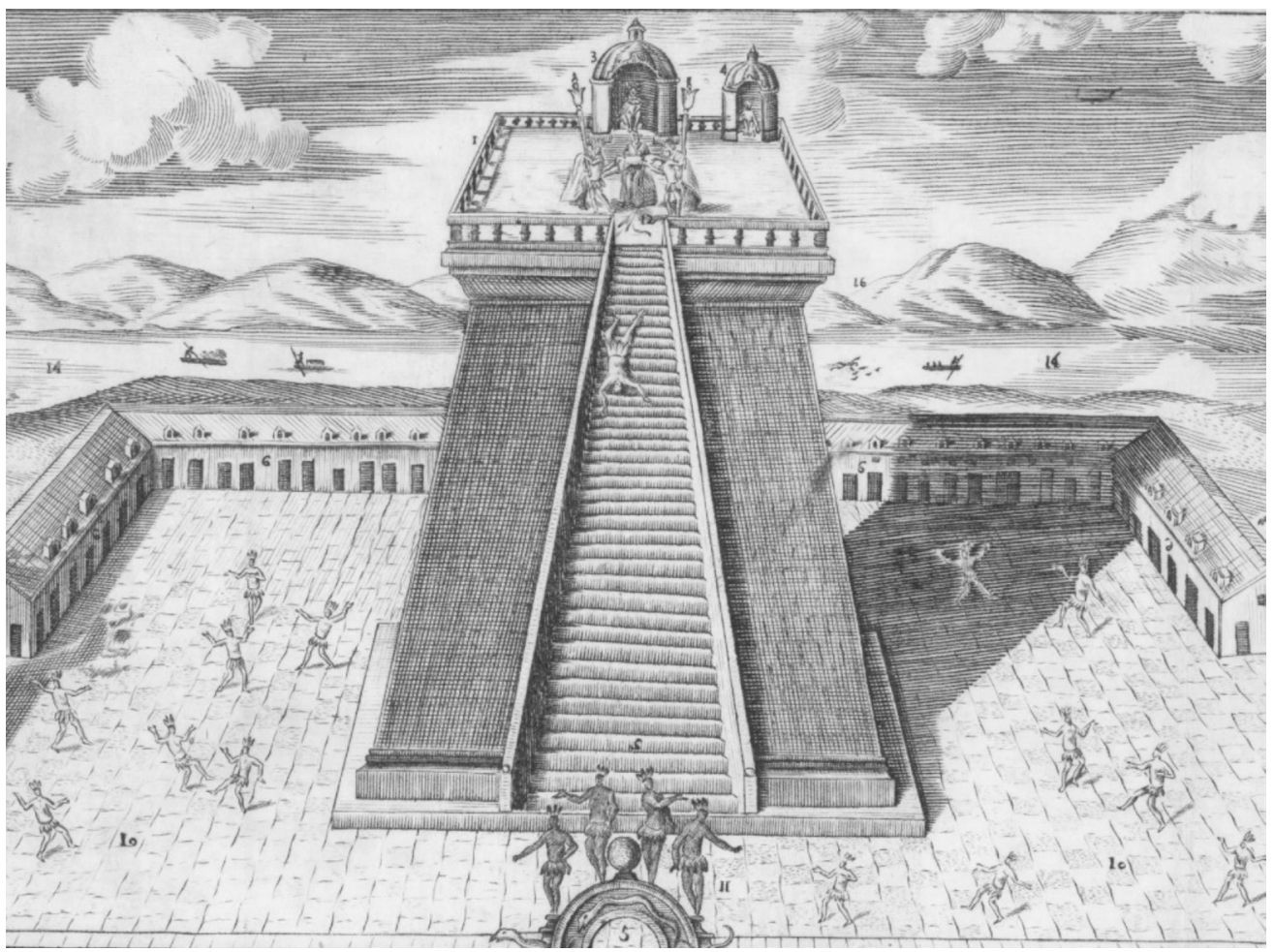

Fig. 12 : représentation du Grand Temple de Mexico publiée par Lorenzana en 1770

Inversement Les autres pyramides sont déformées (cf. fig. 12). La province de Tlapan contient une pyramide dont les degrés sont encore apparents mais l'escalier totalement incompréhensible ${ }^{135}$. La province de Tollocan comprend une pyramide sans degrés apparents, avec une paroi verticale sur la façade et trois marches inutiles en contrebas ${ }^{136}$. La confusion entre marches et degrés de la

côté, sa rampe. Seules les marches de l'escalier ne sont pas apparentes, comme dans Purchas, mais simplement indiquées par des lignes horizontales. Le sanctuaire est simplifié par le glyphe calli (maison).

135 Francisco Antonio de Lorenzana, Historia de Nueva-España..., pl. 19 (Tlappan). Le glyphe est le troisième en partant de la gauche. On distingue une pyramide à 6 degrés (plus la plateforme de base), dont le sanctuaire est remplacé par le glyphe d'une fleur de coton. Sur la gauche on peut deviner un escalier représenté d'une seule volée, avec sa rampe, mais les marches ont été simplifiées en un bloc lisse, et le dessin traditionnel de la rampe est déformé; mais leur séparation de la rampe est bien indiquée.

136 Francisco Antonio de Lorenzana, Historia de Nueva-España..., pl. 12 (Toluca). Le glyphe n'est pas glosé, mais il se trouve dans l'angle inférieur droit. C'est une pyramide à 7 degrés (plus la plateforme de base), avec un sanctuaire simplifié en glyphe calli (maison). Mais ces degrés ne sont indiqués que par des lignes horizontales, et fondus dans la forme de la pyramide. La sorte de paroi verticale sur la gauche (façade de la pyramide) est tout ce qu'il reste de la rampe d'escalier des glyphes traditionnels, incompris ici. Les marches 
pyramide pour Quiyauhteopan ${ }^{137}$ et Ichcateopan ${ }^{138}$ a pu induire Clavijero en erreur, tout comme la pyramide de Tlatelolco sans indication des marches d'escalier, ni de degrés, ce qui rend la compréhension du temple énigmatique (on ne reconnaît plus du coup la représentation des rampes d'escalier, pourtant bien visibles) $)^{139}$.

Ce qui est une des gravures principales de l'œuvre de Clavijero du fait de son grand format qui nécessite de déplier la gravure (cas réservé aux cartes de l'Anahuac et de la lagune de Tezcoco), mais aussi de par sa position dans l'ouvrage (première gravure à représenter la société aztèque) ${ }^{140}$ s'avère un ratage complet : la position des escaliers, la forme des sanctuaires et la taille de la plate-forme sommitale sont erronées. En voulant corriger la version proposée par Lorenzana, Clavijero s'est tourné vers une gravure du Xvie siècle qui s'avère finalement pire que celle proposée en 1770.

\section{Autres représentations erronées en matière de REligion :}

$\mathrm{Au}$ moins trois autres planches reprennent différentes erreurs en matière de religion : la représentation d'un autre temple, et celle de deux modalités de sacrifices humains.

Autre SORTE DE TEMPLE (UN ALTRA FATTA DI TEMPIO, PLANCHE 5) $)^{141}$

Cette gravure est également fortement erronée du fait de la représentation d'une sorte de niche avec statue gréco-romaine sur un socle. La niche présente une voûte supérieure totalement erronée, qui contredit toute l'architecture préhispanique. Ces erreurs sont celles de la gravure du Grand Temple par Diego Valadés ${ }^{142}$

d'escalier ne sont pas visibles, seule la rampe figure sur la gauche de la pyramide.

${ }_{137}$ Francisco Antonio de Lorenzana, Historia de Nueva-España..., pl. 20 (3 provinces tributaires). Quiyauhteopan n'est pas glosé, mais c'est le glyphe inférieur de la province du milieu. On distingue une pyramide à 6 degrés (sans plateforme de base unie), mais la rampe d'escalier au lieu d'être unie, prolonge les degrés de la pyramide. Le sanctuaire est remplacé par 3 gouttes de pluie.

138 Francisco Antonio de Lorenzana, Historia de Nueva-España..., pl. 17 (Tepequacuilco) : anté-pénultième glyphe de lieu. Le glyphe n'est pas glosé. C'est une pyramide à 5 degrés (plus la plateforme servant de base), dont le sanctuaire est remplacé par le glyphe d'une fleur de coton. Mais les marches d'escalier sur la gauche sont confondues avec les degrés de la pyramide, et la rampe est fortement anguleuse. Ce glyphe ou d'autres semblables ont pu induire Clavijero en erreur.

139 Francisco Antonio de Lorenzana, Historia de Nueva-España..., pl. 2 (Tlatelolco).

140 Les trois gravures qui précèdent sont une carte de l'Anahuac (pág. 26'), une planche de fleurs (pág. 40') et une planche d'animaux (pág. 96'), ces deux dernières faisant partie du Livre I que la carte précède.

141 F. Javier Clavijero, Storia Antica..., vol. 1, pág. 34' (tome II, lib. VI).

142 Fr. Diego Valadés, Retórica Cristiana, pág. [389] (pág. 171' de l'édition originale en latin). Clavijero et le graveur qui travaille pour lui reprennent l'édifice principal qui figure au centre de la planche de 
qui a colporté ces erreurs multiples à la fin du Xvie siècle, son livre étant imprimé en Italie en 1579 avec le soutien du Pape.

La statue de la Coatlicue n'a pas encore été trouvée puisqu'elle le sera seulement en 1790, dix ans après la première édition de l'ouvrage de Clavijero, ce qui excuse en partie son erreur concernant la statuaire, même s'il a certainement vu à Mexico des fragments de statues préhispaniques.

\section{SaCrifice humain ordinaire (IL SACRIFIZIo ordinario, Planche 6$)^{143}$}

La principale erreur de cette gravure consiste en la taille démesurée de la pierre de sacrifice qui s'apparente plus à une table (et inspirera jusqu'aux films mexicains de la première moitié du XXe siècle). L'erreur est déjà présente chez Valadès en 1579, dans sa gravure du Grand Temple, totalement fantaisiste ${ }^{144}$. On rapellera que la représentation de pierre de sacrifice de Lorenzana, bien qu'écartée par Clavijero, est finalement meilleure que la sienne ${ }^{145}$.

Le décor des vêtements des prêtres (capes) est une fantaisie géométrique malgré les modèles représentés dans le Codex Mendoza et publiés par Pur$\operatorname{chas}^{146}$.

Par contre les gestes des cinq prêtres auxiliaires pour tenir les membres ou la tête, sont corrects et très certainement inspirés par une scène de codex préhispanique ou colonial ${ }^{147}$.

\footnotetext{
Valadés, en corrigeant les erreurs de perspectives (du coup on ne voit plus les escaliers latéraux, mais on peut deviner leur présence du fait des ouvertures dans le parapet sur les côtés), en enlevant tous les personnages sauf un grand prêtre sur l'escalier, et en déplaçant la statue d'idole vers le centre. Par contre la scène de sacrifice humain a été supprimée, tout comme la pierre de sacrifice. On reconnaît la forme arrondie au bas de l'escalier principal.

143 F. Javier Clavijero, Storia Antica..., vol. 1, pág. 46’ (tome II, lib. VI).

144 Fr. Diego Valadés, Retórica Cristiana, pág. [389] (pág. 171' de l'édition originale en latin). La pierre de sacrifice bien trop longue apparaît dans la niche de l'édifice central. On constate que Clavijero reprend une méthode qu'il affectionne puisqu'il dissocie en au moins trois planches la gravure de Valadés, pour en reprendre différents aspects : religieux (avec un modèle de temple planche 5 puis le sacrifice humain ordinaire planche 6), ou profane (avec la façon de préparer le pain, planche 18); tout comme il dissociait en au moins deux planches la gravure de Valadès concernant le calendrier préhispanique.

145 Francisco Antonio de Lorenzana, Historia de Nueva-España..., pl. El Grande Templo de México. En effet la pierre de sacrifice n'est plus horizontale mais bien verticale et le prisonnier est en partie cambré dessus. Même si la pierre est trop grande, sa représentation est bien plus correcte et conforme aux descriptions des chroniqueurs, que celle de Clavijero inspirée par Valadès.

146 Samuel Purchas, Hakluytus Posthumus..., p. 1111 (Chap. 7, \& 3 Mexican Priests military ensignes and degrees of honour).

${ }_{147}$ Autre que celles du manuscrit Tovar (pl. 21) ou du Codex Magliabechi (f.70r) ou Tudela (f. 53r) puisque les prêtres auxiliaires sont moins nombreux et que les pieds de la victime sont retenus par un seul d'entre eux. Mais certains gestes peuvent avoir été repris isolément et combinés, comme celui de tenir le coeur arraché dans une main (Codex Tudela f. 53r).
} 
La pierre sur laquelle sont juchés les deux combattants est bien un disque de pierre mais totalement lisse. Il n'a pas été rapproché de la Pierre de Tizoc (pourtant présente à la porte de la cathédrale de Mexico depuis la seconde moitié du Xvie siècle), du fait que les gravures sont réalisées en Italie et ne peuvent plus reprendre les détails de ce monument aztèque connu ${ }^{149}$.

Clavijero est cependant capable d'inclure dans ses gravures des éléments archéologiques. Ils sont rares, du fait de la date d'édition de l'ouvrage en 1780, dix ans avant la découverte de deux monolithes emblématiques de la culture aztèque, la Coatlicue et la Pierre du Soleil ${ }^{150}$. Mais la planche 11, consacrée aux éléments militaires, inclut la forme semi-circulaire concentrique des murailles de la ville de Quauhquechollan («Uscio delle muraglie delle Cittta»). Le texte la localise et la décrit en détail ${ }^{151}$.

\section{Conclusion}

Si Carreri détaille les divinités dans son texte, on remarquera qu'il n'y consacre aucune planche dans ses gravures. Pourtant la brèche avait été ouverte dès 1601 par les gravures des couvertures (portadas) des Décades d'Antonio de Herrera, qui reprenaient les gravures d'un codex proche du Codex Magliabechi pour les divinités de l'air (Ehecatl), de la pluie (Tlaloc), de la guerre (Huitzilopochtli) et du pulque ${ }^{152}$.

Clavijero réutilisant les gravures de Gemelli Careri, pouvait également inclure le portrait de Tlaloc adapté au goût renaissance, inspiré d'une planche du Codex Ixtlilxochitl ${ }^{153}$. Il ne l'a pas fait, préférant centrer ses gravures sur la so-

\footnotetext{
148 F. Javier Clavijero, Storia Antica..., vol. 1, pág. 48’ (tome II, lib. VI).

149 Nous avons déjà signalé plus haut les erreurs concernant les armes, boucliers, pagnes ou l'architecture. Cf. Supra, note 110.

150 cf. Antonio de León y Gama, Descripción histórica y cronológica de las dos piedras..., Mexico, INAH, 1990 [1792].

151 F. Javier ClaviJero, Storia Antica..., vol. 1, pág. 150’ (tome II, lib. VII); Historia antigua..., pág. 228 (lib. VII, point 26. Fortificaciones). C'est même l'une des rares fois où l'on trouve une allusion explicite dans le texte principal aux planches qui l'accompagnent : " por más de 40 pasos en forma de 2 semicírculos concéntricos, como se representa en la figura de una de nuestras láminas. »

152 cf. Patrick LESBRE, « Gravures d'inspiration préhispanique dans les Frontispices de l'Historia general de los hechos de los castellanos d'Antonio de Herrera (1601) », E-Spania n 18 [En ligne], juin 2014 URL : http ://e-spania.revues.org/23671.

153 G.F. Gemelli Careri, Viaje a la Nueva España, p. 57. cf. Patrick LesBre, « Illustrations acolhua de facture européenne? (Codex Ixtlilxochitl, ff. 105-112) », Journal de la Société des Américanistes, $\mathrm{n}^{\circ}$ 84-2, 1998, págs. 102-105 et 111-112.
} 
ciété, l'histoire, les glyphes. Il y aurait donc une censure voulue du polythéisme aztèque, malgré la représentation des sanctuaires double du Grand Temple de Mexico, ou celle de deux formes de sacrifices humains.

Il se peut aussi que joue une forme d'incompréhension face aux manuscrits authentiquement préhispaniques. Clavijero fait allusion plusieurs fois dans son texte au manuscrit pictographique conservé à Bologne ${ }^{154}$. Il en décrit l'apparence (peau d'animal, format) mais se garde d'entrer plus en détails dans les contenus. On ne peut que regretter qu'il n'ait pas eu l'audace d'en reproduire quelques scènes ou pages. Humboldt ou Kingsborough se chargeront de publier des pages de codex préhispaniques inédits au début du xIXe siècle ${ }^{155}$, comme pour combler ce manque et produire quelque chose de réellement nouveau en matière de manuscrits pictographiques.

154 F. Javier Clavijero, Historia antigua..., pág. 248 (lib. VII, point 47) : « Otras eran mitológicas , que encerraban los arcanos de su religión, como son las del volumen que se conserva en la biblioteca del Insituto de Bolonia, de que ya hablaremos. "; pág. 249 (lib. VII, point 48. Lienzo y colores) : « El volument de pinturas mexicanas que se conserva en la bilblioteca del Instituto de Bolonia es una piel muy gruesa y mal curtida 0 , por mejor decir, varias unidades de más de 5 varas de largo y como de 8 pulgadas de ancho, pintadas por una y otra parte y plegadas en la forma dicha. » Il s'agit du Codex Cospi, manuscrit préhispanique, contrairement à ceux copiés par Purchas, Lorenzana ou Carreria, qui sont tous coloniaux (Codex Mendoza, Matrícula de Tributos, Mapa de Sigüenza, planches du Codex Ixtlilxochitl).

155 Alexandre de Humboldt, Vues des Cordillères et Monuments des Peuples Indigènes de l'Amérique, Nanterre, Ed. Erasme, 1989 [1810]. Sur les 33 planches concernant le Mexique indien préhispanique (ou censé être préhispanique) 20 sont des scènes ou pages de manuscrits pictographiques. Seuls sont authentiquement préhispaniques le Codex Borgia (planches 15, 27, 37) le Codex Vindobonensis (pl. 46 à 48), le Codex Vaticano $B$ (pl. 13, 60) et le Codex de Dresde (pl. 45), soit 9 planches sur 33 (presque un tiers des planches totales de l'ouvrage). S'y ajoutent le Codex Vaticano A (pl. 14, 26), Telleriano-Remensis (pl. 55-56), la Mapa de Sigüienza (pl. 32) et la Mapa de Huamantla (pl. 38) et une série de fragments rapportés à Berlin (pl. 12, 36 et 57) qui sont coloniaux. 